\title{
An Experimental Analysis of in vivo Guidance Cues Used by Axons of Spinal Interneurons in the Chick Embryo: Evidence for Chemotropism and Related Guidance Mechanisms
}

\author{
Hiroyuki Yaginuma1,2 and Ronald W. Oppenheim ${ }^{1}$ \\ 1Department of Neurobiology and Anatomy and Neuroscience Program, Bowman Gray School of Medicine, Wake Forest \\ University, Winston-Salem, North Carolina 27103 and ${ }^{2}$ Department of Anatomy, Institute of Basic Medical Sciences, \\ University of Tsukuba, Tsukuba 305, Japan
}

To clarify axonal guidance mechanisms involved in pathway formation by spinal interneurons, the pattern of axonal outgrowth was examined following three kinds of perturbations: (1) rotation of three segments of the neural tube around the dorsal-ventral axis by $90^{\circ}$ or $180^{\circ}$ (D-V rotation), (2) rotation of three segments of the neural tube around the rostralcaudal axis (R-C rotation), and (3) transplantation of brainstem into thoracic spinal segments (BS transplantation).

Following D-V rotation, it was observed that circumferential axons near the junction between rotated graft (RG) and host cord changed their course so as to project toward the ectopic floor plate. This supports the notion that the floor plate exerts a chemotropic-like effect on the directional projection of circumferential axons. The longltudinal fibers in the ventral funiculus (VF) were able to grow through the transplant junction when the VF was well apposed to the VF of the RG. However, in most cases, the longitudinal fibers in the VF that were not apposed to the VF of the RG made a medial turn at the junction. After turning, some of them made a U-turn into the contralateral VF, whereas others grew circumferentially around the junction zone, then exited the spinal cord; still others directly entered the RG. The majority of fibers that entered the RG were located in the VF, though a small number of such fibers were also located in both the lateral and dorsal funiculus (LF and DF, respectively). The fibers that entered the LF shifted ventrally, whereas the fibers in the DF remained within the DF. These results suggest that there may be some matching mechanism between specific fibers and the funiculus through which the fibers normally project. Moreover, there may be a barrier between the LF and the DF that prevents the fibers in the DF from shifting ventrally.

In R-C rotation experiments, the projection of axons of dorsolateral border cells (DLB-cells), which are known to give rise almost exclusively to commissural ascending axons, was examined. Following the injection of HRP into the rostral junctional region, retrogradely labeled DLB-cells were

\footnotetext{
Received Aug. 21, 1990; revised Mar. 21, 1991; accepted Mar. 29, 1991

We wish to thank Drs. N. Okado and M. Matsushita for their help and advice, O. Usun and R. Kunzi for their unfailing technical assistance, and A. Frankfurter for providing the $\beta$-tubulin antibody. This study was supported by National Science Foundation Grant BNS 8707290 to R.W.O

Correspondence should be addressed to Ronald W. Oppenheim, Department of Neurobiology and Anatomy, Bowman Gray School of Medicine, Wake Forest University, Winston-Salem, NC 27103.

Copyright (C) 1991 Society for Neuroscience $0270-6474 / 91 / 112598-16 \$ 03.00 / 0$
}

observed in the rotated segments only on the side contralateral to the injection. Labeled DLB-cells were also observed in the segments caudal to the rotated segments. These results suggest that putative rostrocaudal directional cues that guide the axons of DLB-cells may arise from outside of the segments in which the decision to turn is made. However, once the axons begin to project longitudinally, they appeared to ignore rostrocaudal and laterality cues in the pathway.

Following brainstem transplantation, both anterogradely and retrogradely labeled longitudinal fibers were found to pass through the transplanted graft without major disturbance at the junctions. This suggests that the guidance cues in the marginal zone are not specified based on the position of the marginal zone along the rostral-caudal axis of the neural tube.

Previous studies have demonstrated that intersegmentally projecting interneurons pioneer the first longitudinal pathways in the avian spinal cord, prior to the formation of supraspinal descending systems (Ramón y Cajal, 1929; Windle and Orr, 1934; Hollyday and Hamburger, 1977; Holley, 1982, 1987; Okado and Oppenheim, 1985; Hollcy and Silver, 1987; Oppenheim et al., 1988; Shiga et al., 1990; Yaginuma et al., 1990). Early developing interneurons can be subdivided into two groups: primitive longitudinal cells (PL-cells) and circumferential cells (C-cells; Yaginuma et al., 1990). PL-cells develop in the region between the floor plate and the motor neuron nucleus, and their axons project rostrally or caudally in the ventral marginal zones to pioneer a primitive longitudinal association pathway (Shiga et al., 1990; Yaginuma et al., 1990). C-cells are distributed along most of the dorsoventral plane of the neural tube. Their axons project ventrally along the lateral border of the neural tube, and some of them enter the ipsilateral ventral longitudinal pathway, whereas others (commissural C-cells) cross the midline to join the contralateral longitudinal pathway (Holley, 1987; Holley and Silver, 1987; Shiga et al., 1990; Yaginuma et al., 1990).

Various kinds of axonal guidance mechanisms are thought to be involved in pathway formation by spinal interneurons (Dodd and Jessell, 1988). In vitro studies suggest that chemotropism may play a role in the guidance of commissural circumferential axons toward the floor plate in the rat (Tessier-Levigne et al., 1988). A number of descriptive and experimental studies have been done in fish and amphibians on guidance mechanisms used by spinal axons in longitudinal pathways. Longitudinally ori- 
ented preexisting channels or tunnels were observed in advance of developing axons in the newt and Xenopus laevis (Singer et al., 1979; Nordlander and Singer, 1982). Kuwada (1986) demonstrated, in Japanese medaka fish, that axons of Rohon-Beard cells (RB-cells) pioneer the dorsolateral fascicle by utilizing cues provided by neuroepithelial cells, and that later-developing axons in this pathway must specifically fasciculate with axons of RB-cells in order to establish normal projections. These observations are consistent with the "substrate" or "labeled pathway" hypothesis, which postulates that the axon guidance cues for many long CNS axon tracts are aligned as continuous or discrete pathways in the substrate (Katz and Lasek, 1979, 1981; Katz et al., 1980; Goodman et al., 1982; Raper et al., 1983b). Perturbation studies in frogs have demonstrated that particular populations of axons exhibit preferences for specific pathways (Constantin-Paton and Capranica, 1976; Katz and Lasek, 1979, 1981; Huang and Jacobson, 1986; Holder et al., 1987), and that axons have the ability to navigate abnormal routes to reach their preferred pathway (Huang and Jacobson, 1986; Holder et al., 1987). However, interactions with a specific pathway do not appear to control either the rostrocaudal polarity or laterality of the projections (Huang and Jacobson, 1986; Holder et al., 1987).

In the present study, we attempted to clarify what kinds of mechanisms play a role in the axonal guidance of spinal interneurons in the chick embryo. We have examined the pattern of axonal outgrowth following perturbation of putative positional and directional cues by (1) rotation of a few spinal segments around the dorsal-ventral axis (D- $V$ rotation), (2) rotation of a few segments around the rostral-caudal axis ( $\mathrm{R}-\mathrm{C}$ rotation), and (3) placement of brainstem grafts into thoracic segments (BS transplantation). These operations were made before the initiation of axonogenesis of the earliest-developing interneurons.

Part of this study has been published in abstract form (Yaginuma et al., 1988).

\section{Materials and Methods}

Embryos. Fertilized eggs (a gift from Hubbard Farms, Statesville, NC) were incubated in a forced-draft rotating incubator at $38^{\circ} \mathrm{C}$ and $60 \%$ relative humidity until they reached the appropriate age [stages (ST) 14-15, or ST11-12 for brainstem donors). Windows were made in the shell, and embryos were visualized by staining with neutral red and were precisely staged using the Hamburger and Hamilton (1951) morphological stage series.

Operations. Three kinds of operations were performed: (1) transplantation of three segments of the neural tube following rotation around the dorsal-ventral axis (D-V rotation), (2) rotation of three segments of the neural tube around the rostral-caudal axis ( $R-C$ rotation), and (3) transplantation of the brainstem into the thoracic segments of the neural tube (BS transplantation). In the D-V rotation experiments (Fig. 1A), the neural tube and the notochord adjacent to the final three somites were removed from a donor embryo and transferred into the egg of the host embryo, whose developmental stage was identical with the donor embryo. A gap was made in the host neural tube by removing the neural tube and notochord adjacent to the final three somites. The graft was placed in the gap with rotation around the dorsoventral axis of either $90^{\circ}$ or $180^{\circ}$. In the R-C rotation experiments (Fig. $1 B$ ), three segments of neural tube adjacent to the final three somites were removed together with notochord, rotated about the rostrocaudal axis, then replaced in the same embryo. This resulted in a reversal of both rostral-caudal direction and laterality (right-left). In the BS transplantation experiments (Fig. 1C), hindbrain located adjacent and caudal to the otocyst was taken together with attached notochord from a younger donor embryo (ST 1 1-12) and transferred into the egg of a host embryo of ST 14 15. A gap that fit the rostral-caudal dimensions of the caudal hindbrain graft was made in the host neural tube adjacent to the most caudal somites. The graft was placed in the gap in a normal rostrocaudal and
A dorso-ventral rotation
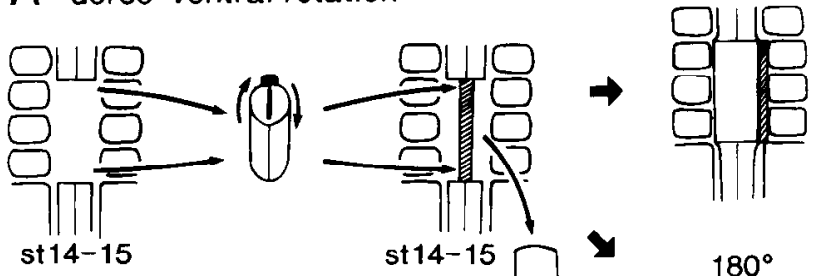

$180^{\circ}$

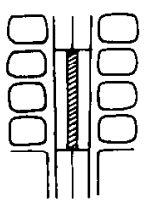

$90^{\circ}$

$\mathrm{B}$ rostro-caudal rotation

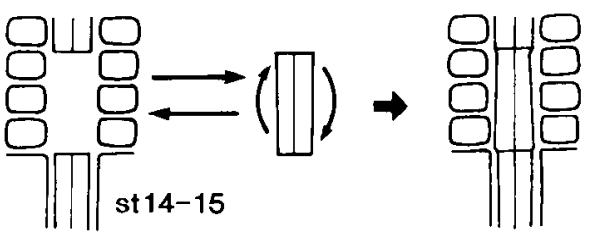

C brainstem transplant

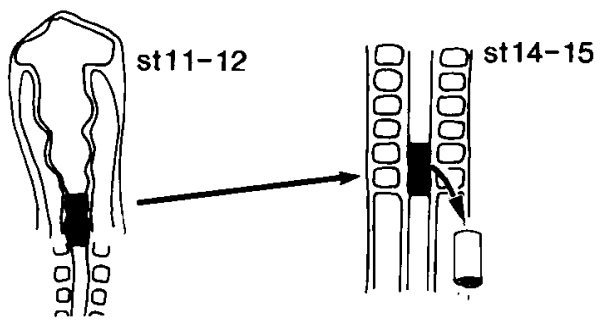

Figure 1. Diagrams showing the surgical perturbations. $A, \mathrm{D}-\mathrm{V}$ rotation. In this experiment, three segments of the neural tube, together with the notochord (hatched), that were adjacent to the last three somites were taken from a donor embryo of ST 14-15, then transplanted into a host embryo whose three segments of neural tube adjacent to the last three somites were removed, but whose notochord was left intact. The graft was placed with either $90^{\circ}$ or $180^{\circ}$ rotation. $B, \mathrm{R}-\mathrm{C}$ rotation. Three segments of the neural tube and the notochord that were adjacent to the last three segments were removed from an embryo of ST14-15, rotated rostrocaudally, then replaced into the same embryo. $C$, BS transplantation. The caudal portion of the hindbrain and adjacent notochord were taken from a donor embryo of ST11-12, then transplanted into thoracic segments of a host embryo of ST14-15.

dorsoventral orientation. As controls, operations were made in which the neural tube was removed but replaced without rotation, and in which the neural tube was transplanted without rotation. After completion of the operations, the window in the shell was closed with Parafilm, and the eggs were returned to the incubator.

$H R P$ and DiI labeling. On embryonic day (E) 6, embryos were removed from the egg and placed into a Sylgard-lined dish containing cold, oxygenated $\left(95 \% \mathrm{O}_{2}, 5 \% \mathrm{CO}_{2}\right)$ avian Tyrode's solution. Embryos were eviscerated, and a ventral laminectomy was performed. The sites of transplantation were examined, and only embryos in which the operated graft appeared normal and was well incorporated with host neural tube were used for further examination. Horseradish peroxidase (HRP; Sigma, type VI) was then administered using Minuten insect pins. In cases of D-V rotation or BS transplantation, injections wcrc made cither uni- or bilaterally into regions two or three segments rostral to the rostral junction of the transplant. In cases with $\mathrm{R}-\mathrm{C}$ rotation, injections were made unilaterally into either the rostral or caudal junctional region. The embryos were transferred immediately to another Sylgard-lined dish containing fresh, circulating, oxygenated Tyrode's solution at a temperature of $25^{\circ} \mathrm{C}$, pinned to the bottom of the dish with stainless-steel insect pins, and maintained for 12-15 hr. The embryos were immersion fixed overnight with $2.5 \%$ glutaraldehyde in $0.1 \mathrm{M}$ phosphate buffer $(\mathrm{pH}$ $7.3)$ at $4^{\circ} \mathrm{C}$ and embedded into a gelatin-egg yolk mixture as described previously (Oppenheim et al., 1988). Vibratome sections ( $80 \mu \mathrm{m}$ thick) 

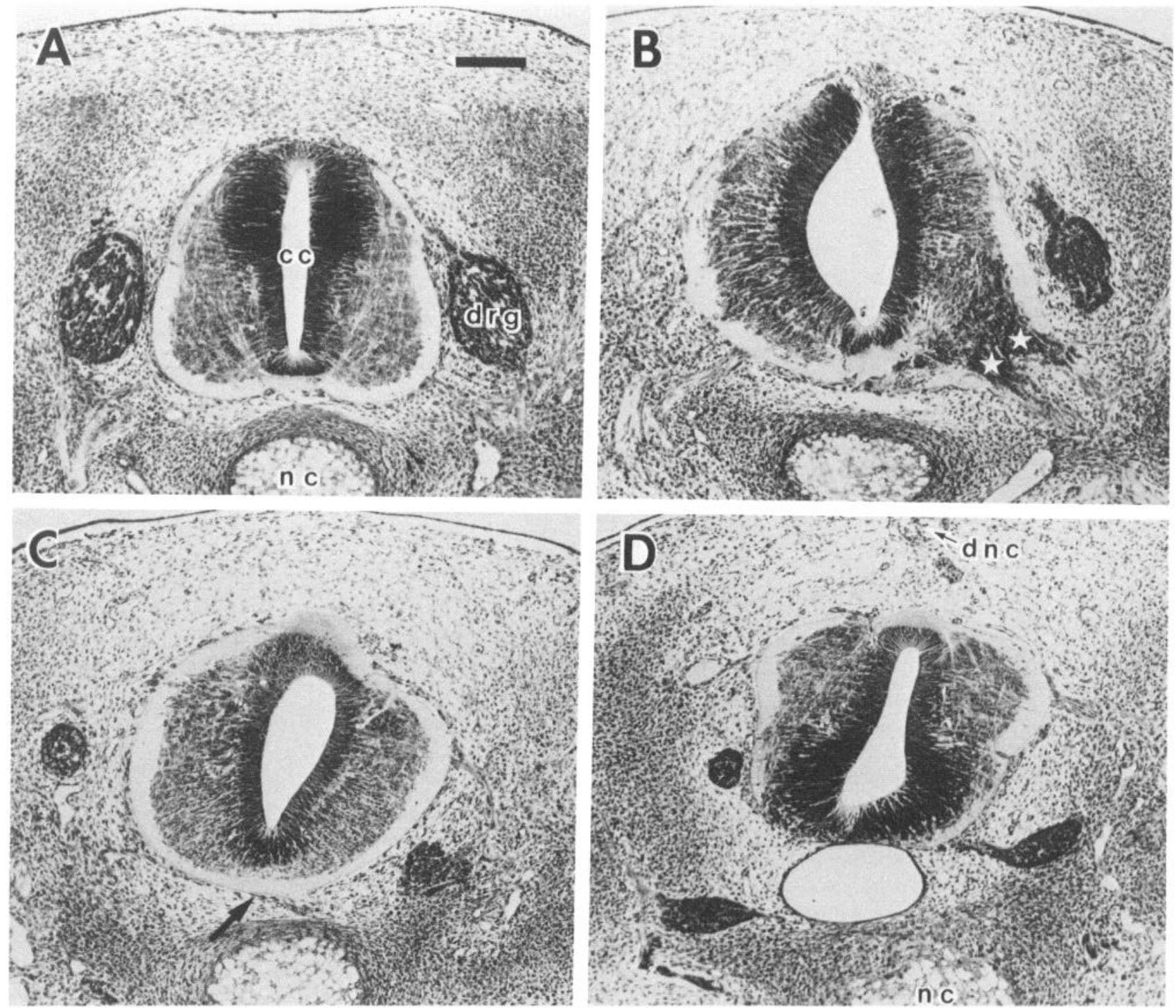

Figure 2. Photomicrographs of transverse sections through thoracic segments of a host embryo with $180^{\circ} \mathrm{D}-\mathrm{V}$ rotation. Dorsal side of the host embryo is upward. A, A section through the rostral unrotated host spinal cord some distance away from the RG. The morphology is the same as the control cases. The ventricular zone, which is stained darker, is widest in the dorsal region (alar plate) and thinnest in the ventral region (basal plate) of the spinal cord. The MZ is located on the lateral and the ventral sides of the neural tube but not over the roof plate. $B$, A section through the junctional region. Note the disorganized structure of the spinal cord and rounded central canal and cells that appear to migrate out of the spinal cord (stars) along fiber bundles. Dorsoventral differences in the thickness of the ventricular zone have largely disappeared. $C$, A section through the transition zone (within $200 \mu \mathrm{m}$ from the junction). Disorganization of the ventricular zone still remains. The MZ surrounded the entire surface of the neural tube, including the roof plate (arrow; cf. with $A$ and $D$ ). $D$, A section through the middle portion of the RG. Organization of the spinal cord appears normal except for reversed dorsal-ventral polarity. $c c$, central canal; $d n c$, donor notochord; $d r g$, dorsal root ganglion; $n c$, host notochord. Scale bar, $100 \mu \mathrm{m}$.

were cut in the transverse plane. HRP histochemistry was done by using diaminobenzidine (DAB) as the chromogen. The sections were mounted on gelatin-subbed slides, dehydrated, and coverslipped with Permount. Sections were observed with the light microscope, and the fiber course of labeled longitudinal fibers was traced. In several cases, the projection patterns of the longitudinal fibers were also examined in whole-mount preparations of the spinal cord. For this, the spinal cord was dissected out from the embryo, connective tissue surrounding the spinal cord was removed as much as possible using forceps and tungsten needles, and the spinal cord was rinsed for several days in the buffer and then processed for whole-mount HRP histochemistry (Tosney and Landmesser, 1986). Projection patterns of labeled longitudinal fibers were drawn using a drawing tube, after which the spinal cord was embedded into the gelatine-egg yolk mixture and sectioned into serial transverse sections. Sections were collected onto slides, dehydrated, coverslipped with Paramount, and observed.
Anterograde labeling of axons with $1,1^{\prime}$-dioctadecyl-3,3,3', $3^{\prime}$,-tetramethylindocarbocyanine perchlorate (DiI; Molecular Probes) was used to examine the projections of commissural neurons in whole-mounts on E6 following R-C rotation performed on E2. E6 embryos were removed from the egg and immersion fixed overnight with $4 \%$ paraformaldehyde in $0.1 \mathrm{~m}$ phosphate buffer $(\mathrm{pH}$ 7.3). Under a dissecting microscope, one side of the spinal cord that included the rotated region was exposed using fine forceps and tungsten needles. A small amount of DiI dissolved in a mixture of ethanol and dimethyl sulfoxide (9:1) was pressure injected into the dorsal portion of the manipulated segments through a glass micropipette. Following 3-5 d of incubation in the dark at $37^{\circ} \mathrm{C}$, the spinal cord, including the injection site, was dissected from the embryo, and its dorsal portion was removed. The ventral portion of the spinal cord was mounted on a slide, on which a coverglass was glued as a spacer, with its ventral side up, and then coverslipped with phosphate buffer. The slide was observed and photographed with 
an epifluorescent microscope with a filter set for rhodamine. A total of two normal control embryos, three unrotated, sham-operated embryos, and five R-C-rotated, operated embryos were observed following Dil injection.

Immunohistochemical labeling. On E3.5 (ST19-21), some embryos with both $\mathrm{D}-\mathrm{V}$ rotation and $\mathrm{R}-\mathrm{C}$ rotation were immersion fixed with $4 \%$ paraformaldehyde in $0.1 \mathrm{~m}$ phosphate buffer $(\mathrm{pH} 7.3)$ for several hours. The neural tubes, including operated sites, were removed using fine tungsten needles. Following thorough washing with phosphate-buffered saline, the neural tube was processed for immunohistochemistry using the $\beta$-tubulin antibody ( $\mathrm{TuJ} 1$ ) as the primary antibody, as described previously (Yaginuma et al., 1990). This antibody, kindly provided by Dr. A. Frankfurter at the University of Virginia (Charlottesville, VA), is known to recognize neuron-specific $\beta$-tubulin in the chick. After immunohistochemistry, the neural tubc was coverslipped with gelatin-glycerol and observed in the light microscope. Immunostained early developing interneurons were drawn using a drawing tube.

Histological examination. Several animals from each kind of experimental procedure were fixed with Carnoy's fixative on E6 and processed for Nissl staining to examine the histology of the spinal cord including the site of operation.

\section{Results}

Rotation around the dorsoventral axis $\left(90^{\circ}\right.$ or $180^{\circ} \mathrm{D}-\mathrm{V}$ rotation)

Histology

In the middle of the rotated graft (RG), the organization of the spinal cord was similar both to the control spinal cord and to unrotated host spinal cord located some distance from the RG (cf. Fig. $2 A, D$ ). Thus, as reported previously (Jacob et al., 1976; Narayanan, 1970), the avian neural tube that was rotated $90^{\circ}$ or $180^{\circ}$ dorsoventrally on $\mathrm{E} 2$, together with adjacent notochord, develops a relatively normal organization and cytoarchitecture relative to the position of the adjacent notochord. At the junction between the $\mathrm{RG}$ and the unrotated host spinal cord, various degrees of structural disorganization were observed (Fig. 2B). These included rounded central canal, disappearance of the dorsoventral differences in the size of the ventricular zone, disappearance of a normal roof-plate-like structure, cells and fiber bundles growing out of the spinal cord, and a disorganized marginal zone (MZ). There were often transition zones between the junctional region and those segments with a normal organization in both the RG and in the unrotated host spinal cord. In these zones, the above-mentioned disorganization tapered off from the junctional region (Fig. 2C). The length of these zones was around $200 \mu \mathrm{m}$ in the $\mathrm{RG}$, though this varied in individual cases. The length of the transition zones in the unrotated host cord always tended to be shorter than that in the RG. These transition zones were observed only in the cases with D-V rotation and were not seen in R-C rotation or BS transplantation. Thus, in analyzing the pathways taken by host axons upon encountering the transplant, the presence or absence and the extent of disorganization in the transition zone of each animal were taken into account.

\section{Projection pattern of the longitudinal fibers in E6 embryos}

Because supraspinal descending projection fibers have reached the lumbar scgments by E6 (Okado and Oppenheim, 1985), we could not distinguish whether the labeled fibers in the D-V rotation animals belonged to supraspinal descending systems or to propriospinal (intersegmental) systems. It is possible that the behavior of the labeled host longitudinal fibers at the junctional regions is affected by differences in their cells of origin. To address this problem, we made complete spinal gaps at the
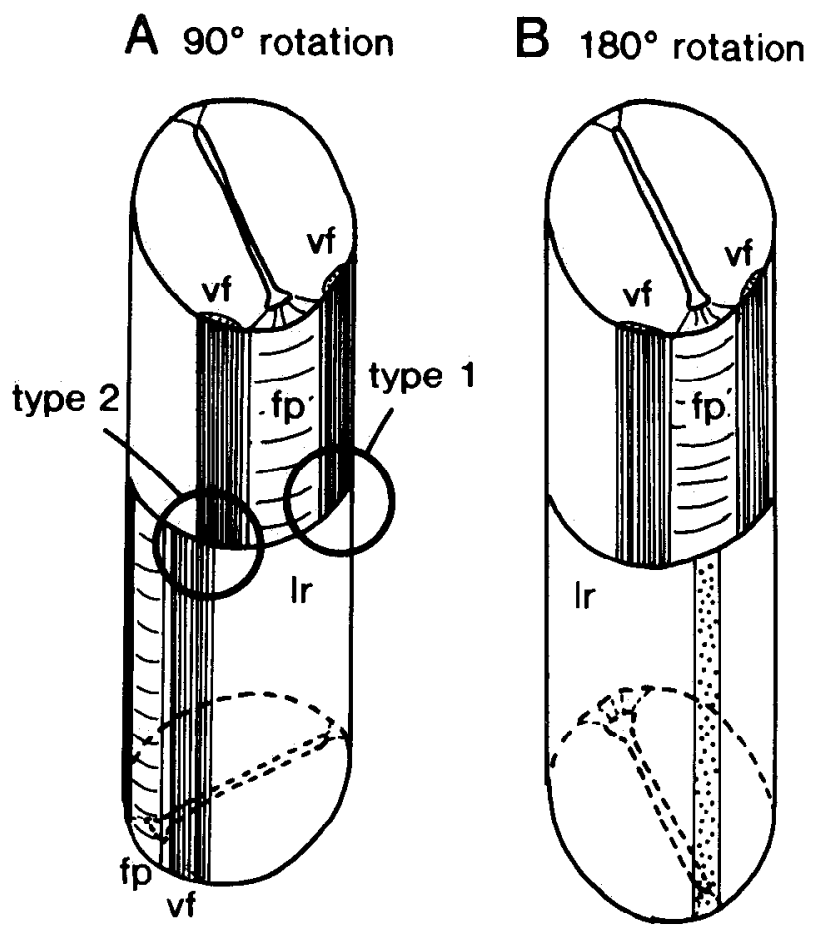

Figure 3. Schematic drawings showing how the ventral MZ (VF) of the rostral host spinal cord is apposed with the rotated spinal cord after $90^{\circ}$ and $180^{\circ} \mathrm{D}-\mathrm{V}$ rotation. $A$, After $90^{\circ}$ rotation, the ventral $\mathrm{MZ}$ of the rostral host spinal cord is apposed either with dorsolateral region of the rotated spinal cord (type 1 junction) or with ventrolateral region of the rotated spinal cord, including part of the ventral $\mathrm{MZ}$ (type 2 junction). $B$, After $180^{\circ}$ rotation, the ventral $\mathrm{MZs}$ of both sides of the rostral host spinal cord are apposed with the dorsolateral region of the rotated spinal cord. $v f$, ventral MZ (VF); $f p$, floor plate (horizontal stripes); lr, lateral region of the spinal cord; $r p$, roof plate (stippled).

cervical level on E2 to prevent the ingrowth of all descending inputs. Because we did not detect any differences in behavior of the labeled fibers at the junctional regions on E6 between transplanted animals with and without descending input, in the following description we have pooled the results from the two kinds of operations.

$90^{\circ} \mathrm{D}-\mathrm{V}$ rotation. Following a $90^{\circ}$ rotation, axons in the host and transplant cord must alter their trajectory as they grow between the two regions if they are to maintain their normal in situ pathways. For example, axons in the host ventral $\mathrm{MZ}$ apposed to the dorsal MZ of the transplant (type 1 junction; Fig. 3) would have to shift their trajectory ventrally in order to locate their normal pathway in the ventral $\mathrm{MZ}$ of the transplant. Alternatively, these axons could continue to project longitudinally by growing into and through a region of the transplant cord that represents an aberrant pathway. For instance, host axons in the ventral $\mathrm{MZ}$ could grow into and through the dorsolateral $\mathrm{MZ}$. Axons could also stop growing upon encountering an aberrant pathway, or they could continue to grow more or less randomly. In the type 2 junction (Fig. 3), host axons in the ventral $\mathrm{MZ}$ are in the vicinity of the transplant ventral $\mathrm{MZ}$ and thus would be expected to project directly across the junction without altering their pathway.

In cases where host axons growing in the ventral MZ, following $90^{\circ}$ rotation, were apposed to the dorsal or dorsolateral $\mathrm{MZ}$ 


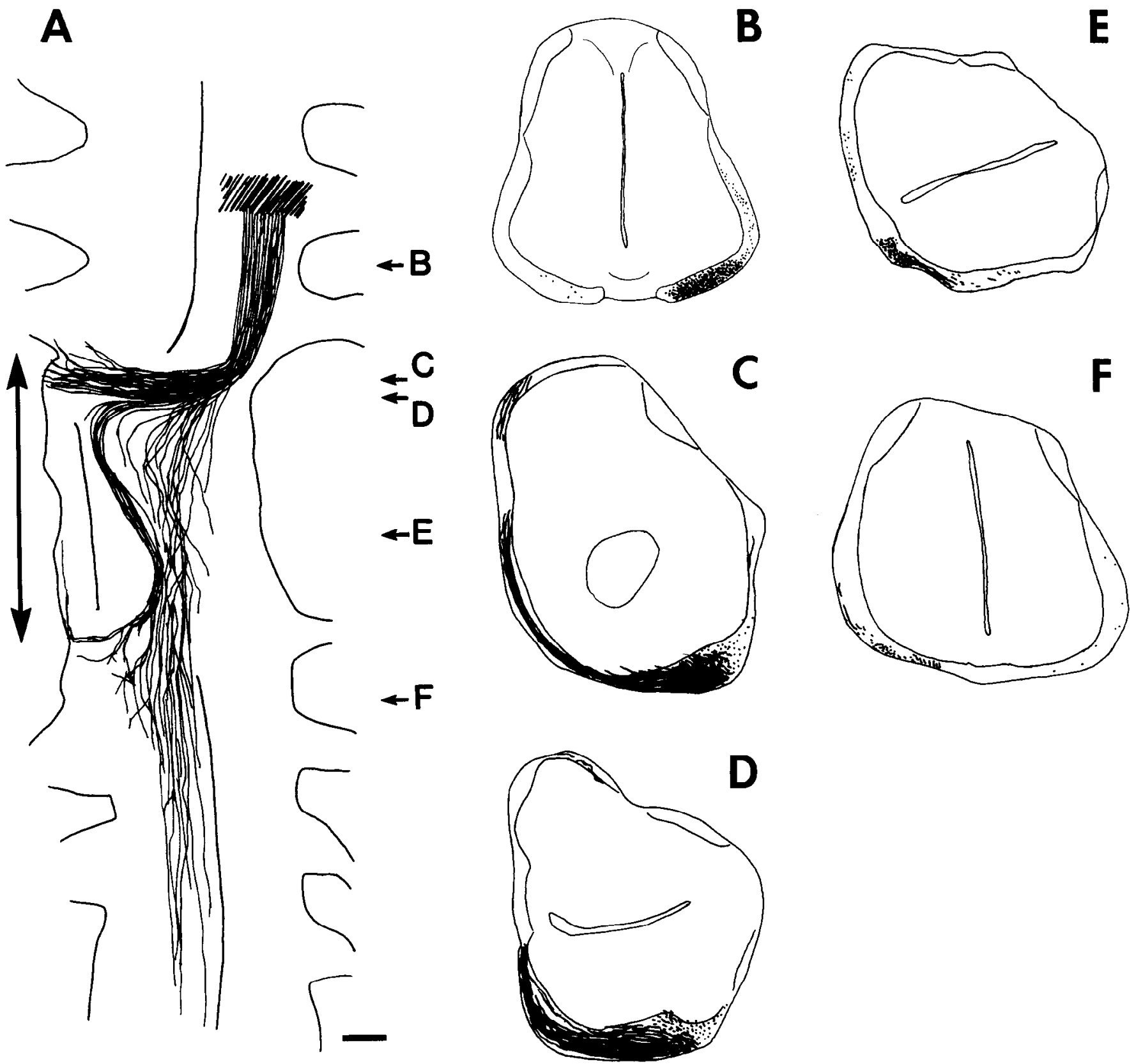

Figure 4. Camera lucida drawings showing the course of the HRP-labeled longitudinal fibers in an animal with $90^{\circ} \mathrm{D}-\mathrm{V}$ rotation toward the apparent right side. $A$, Ventral view of a whole-mount preparation of the spinal cord. Rostral is toward the top. The double-headed arrow indicates the extent of transplant. Scale bar, $100 \mu \mathrm{m} . B-F$, Transverse sections of the same spinal cord in $A$ with levels indicated by arrows in $A$. HRPlabeled longitudinal fibers, which are mainly anterogradely labeled and located in the ventral MZ of the right side $(B)$, make a medial turn at the rostral junction between unrotated segments $(C, D)$ and the $\mathrm{RG}$ and then advance circumferentially. Although some of them grow out of the spinal cord or turn into the contralateral ventral MZ to project rostrally, a considerable number of fibers enter the RG $(E, F)$. In the RG, the labeled fibers are located in the ventral and lateral MZs. However, fibers in the lateral MZ tend to shift ventrally. At the caudal junction, some fibers make a medial turn (medial for the RG), but most fibers continue to grow into the ventral MZ of the left side of the unrotated caudal segments. Crosssectional axons (stippled); axonal processes (solid black lines).

of the transplant (type 2 junction; Fig. 3), virtually all axons shifted medially toward the ventral MZ of the transplant. Many of these then entered the transplant ventral $\mathrm{MZ}$ and projected longitudinally along their normal pathway. Thus, in these cases, axons altered their trajectory so as to locate their normal pathway in the MZ. Moreover, upon reaching the caudal extent of the transplant, they once again shifted their trajectory in order to locate their normal pathway in the ventral $\mathrm{MZ}$ of the caudal host cord. In other cases, axons in the host ventral MZ turned medially, but then entered the contralateral ventral MZ of the host and projected longitudinally in the rostral direction. Thus, in these cases, axons were also able to alter their trajectory so as to locate their normal pathway in the ventral $\mathrm{MZ}$, but rather than projecting caudally, they made a U-turn and reentered and projected rostrally through the host cord. Finally, a few axons grew aberrantly out of the spinal cord after turning medially. This behavior appeared to be correlated with the presence of disorganized neural tissue in the transition zone between host and transplant cord.

In a representative animal presented in Figure 4, most of the 
labeled fibers, which appeared to be anterogradely labeled, were located in the ventral $\mathrm{MZ}$ of the unrotated rostral host spinal cord (Fig. $4 A, B$ ). At the rostral junctional region, these labeled fibers turned medially and ran circumferentially. Although some fibers exited the spinal cord, many fibers also entered the RG (Fig. $4 A, C, D$ ). The majority of these entered the contralateral ventral $\mathrm{MZ}$ in the transplant. A small number of fibers entered the contralateral lateral $\mathrm{MZ}$ of the $\mathrm{RG}$, but they then gradually shifted to the ventral $\mathrm{MZ}$ (Fig. $4 A, E$ ). At the caudal junctional region, most of the fibers advanced directly into the ventral $M Z$ of the unrotated caudal host spinal cord without making turns (Fig. $4 A, F$ ). However, a small number of labeled fibers turned medially, and a few of them turned into the contralateral ventral MZ to project rostrally (Fig. $4 A$ ). Consequently, some of the longitudinal fibers in the ventral $\mathrm{MZ}$ of the rostral unrotated (host) spinal cord were able to grow through the transplant to reach the ventral $\mathrm{MZ}$ of the caudal host spinal cord, though their laterality was now changed from right to left. In summary, following $90^{\circ} \mathrm{D}-\mathrm{V}$ rotations, a majority of axons in the host ventral $\mathrm{MZ}$ were able to alter their trajectory upon encountering an abnormal pathway in the transplant so as to relocate and project within their normal pathway. Similarly, upon reaching the caudal boundary of the transplant, many axons were again able to alter their direction of growth so as to locate the normal pathway in caudal host cord.

$180^{\circ} \mathrm{D}-\mathrm{V}$ mtation. After $180^{\circ} \mathrm{D}-\mathrm{V}$ rotation, the ventral MZs of the unrotated host spinal cord and the $\mathrm{RG}$ were apposed to the dorsolateral MZs of their counterparts at both the rostral and caudal junctional regions (Fig. 3). In these cases, correct pathway behavior would require host axons that encounter the transplant to alter their pathway by growing dorsally in the transplant to locate their normal pathway that has been shifted by $180^{\circ}$. Alternatively, axons could alter their pathway at the transplant border so as to locate and project rostrally in the correct pathways in the contralateral host ventral $\mathrm{MZ}$. In contrast, failure to correct pathway choice could entail (1) growth of host axons from the ventral and ventral-lateral $\mathrm{MZ}$ into the dorsal $\mathrm{MZ}$ of the graft, (2) cessation of growth upon contacting the transplant, or (3) random undirected growth into and within the transplant.

In the example shown in Figure 5, labeled fibers were located hilaterally in the ventral and lateral $\mathrm{MZ}$, but not in the dorsal $\mathrm{MZ}$, of the unrotated rostral host spinal cord (Fig. 5B). Most of the fibers in the lateral $\mathrm{MZ}$ made a dorsal turn at the junctional region and then projected circumferentially along the dorsal margin of the junctional region to reach the contralateral lateral $\mathrm{MZ}$ (Fig. 4C), at which point many fibers appeared to turn rostrally (U-turn). Thus, in these cases, axons were able to alter their projection upon encountering the transplant so as to locate their normal pathway in the lateral MZ, but rather than projecting caudally through the transplant, they made a U-turn and projected rostrally in the host lateral MZ. Labeled fibers in the ventral $\mathrm{MZ}$ turned medially at the rostral junctional region to project circumferentially, after which some fibers then appeared to make U-turns and grow rostrally in the contralateral ventral MZ (Fig. 5A). However, a number of labeled fibers directly entered the RG. Most of these labeled fibers were located in the ventral $\mathrm{MZ}$, though a few remained in the dorsal $\mathrm{MZ}$ of the $\mathrm{RG}$, which is an incorrect pathway for these axons (Fig. $5 E$ ). These fibers remained within the dorsal $\mathrm{MZ}$, and some of them passed through the caudal junctional region to enter the ventral $\mathrm{MZ}$ of the unrotated caudal spinal cord (Fig. $5 A, F$ ). In summary, following $180^{\circ} \mathrm{D}-\mathrm{V}$ rotation, a majority of axons in the host lateral and ventral $\mathrm{MZ}$ were able to alter their trajectory upon contacting the transplant so as to locate their correct pathways. In some cases, this meant growing rostrally in the contralateral host MZ, whereas in others, axons were able to locate the correct pathway in the transplant and continue to project caudally through the transplant. In these latter cases, the axons were also able to alter their trajectory at the caudal boundary so as to locate their correct pathway in the ventral and lateral $\mathrm{MZ}$ of the caudal host cord. A few host axons in the ventral and lateral $\mathrm{MZ}$ projected aberrantly into and through the dorsal $\mathrm{MZ}$ of the transplant and then reentered the ventral $\mathrm{MZ}$ in the caudal host cord. Similar results have been recently reported following transplantation of a $180^{\circ} \mathrm{D}-\mathrm{V}$-rotated portion of quail neural tube into chick embryos (Tanaka et al., 1990). Axons in the host chick ventral MZ altered their pathway within the quail transplant so as to locate and project within the quail ventral marginal zone.

\section{Pattern of axonal outgrowth of the early-developing interneurons}

The results described above were obtained from embryos examined on E6 following spinal cord rotation on E2. In order to examine the pattern of axonal outgrowth of the earliestdeveloping interneurons following $\mathrm{D}-\mathrm{V}$ rotation, whole-mount preparations of spinal cords of E3.5 embryos were stained immunohistochemically with an antibody against neuron-specific $\beta$-tubulin. Normally, intersegmentally projecting interneurons initially project ventrally along the lateral border of the neural tube (C-cells), with the exception of a small number of neurons located in the ventral region that normally project longitudinally to pioneer the ventral longitudinal pathway (PL-cells; Yaginuma et al., 1990). The projection pattern of neither cell type was disturbed in the embryos with control sham operations (transplantation without $\mathrm{D}-\mathrm{V}$ rotation). In the embryos with $\mathrm{D}-\mathrm{V}$ rotation, the pattern of axonal outgrowth both in the circumferential pathway and in the ventral longitudinal pathway was observed in the junctional region between transplant and host, and thesc patterns are described below.

Circumferential pathway. Transplantation of grafts with a $90^{\circ}$ $D-V$ rotation created a junction where the lateral regions of the host neural tube were apposed with either the ventral or the dorsal regions of the transplant. A change in the pattern of outgrowth of the circumferential axons was observed in the region where the lateral and ventral regions were apposed. In those regions, axons of the C-cells located within $100-150 \mu \mathrm{m}$ from the junction turned longitudinally toward the floor plate, which was now located in an ectopic position for these circumferential axons (Figs. 6, 7A). In contrast, circumferential axons in the host that were located farther away from the junction $(>150 \mu \mathrm{m})$ did not change their fiber course. Moreover, in the region near the junction where the lateral regions were apposed with the dorsal regions (roof plate), and which thus lacked an ectopic floor plate, the pattern of outgrowth of the circumferential axons was not disturbed (Fig. $7 B$ ). Thus, the turning bchavior observed when lateral and ventral regions are apposed cannot be attributed to the surgical procedure. In animals with $180^{\circ} \mathrm{D}-\mathrm{V}$ rotations, it was observed that the axons of the circumferential neurons whose cell bodies were located in the dorsal region near the junction grew toward and across the junction, and then turned toward the ectopic floor plate (Fig. $7 \mathrm{C}$ ). In all 

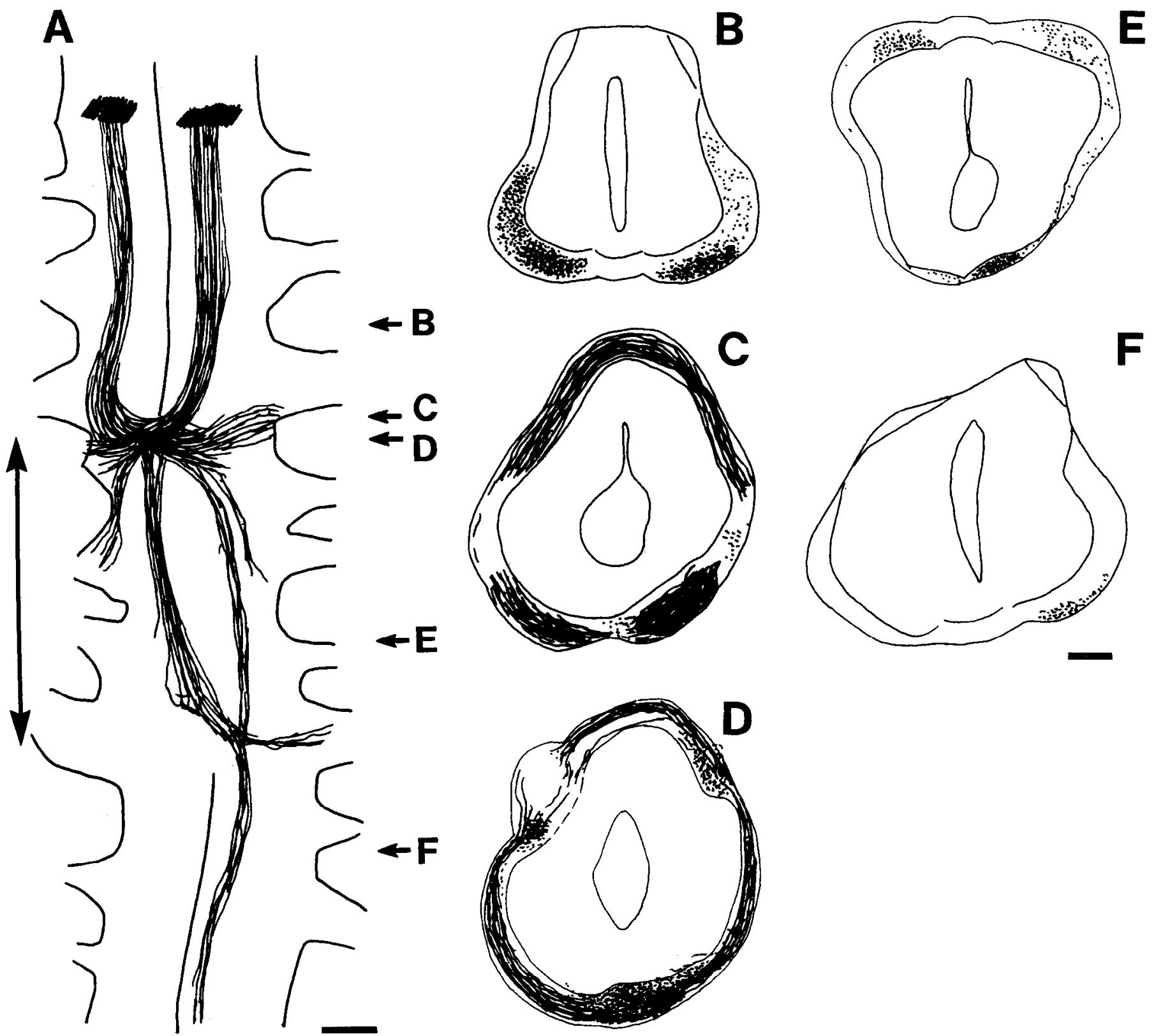

Figure 5. Camera lucida drawings showing the course of HRP-labeled longitudinal fibers in an animal with $180^{\circ} \mathrm{D}-\mathrm{V}$ rotation. $A$, Ventral view of a whole-mount preparation of the spinal cord. Rostral is toward the lop. The double-headed arrow indicates the extent of transplant. Scale bar, $100 \mu \mathrm{m} . B-F$, Transverse sections of the same spinal cord shown in $A$. In the rostral unrotated segments $(B)$, the longitudinal fibers, which were labeled by bilateral injection of HRP, are located bilaterally in the ventral and lateral MZs but not in the dorsal MZ. [Conclusions about laterality and midline crossing of labeled axons (see Materials and Methods) were contirmed in cases with unilateral injection of $H R P$.] At the rostral junction $(C, D)$, fibers in the LF appear to make a dorsal turn and advance circumferentially along the dorsal border of the spinal cord to reach the contralateral lateral MZ. There, most fibers turn rostrally. The fibers in the ventral MZ make a medial turn at the rostral junction, then advance circumferentially. Many fibers make U-turns to either enter the contralateral VF or grow out of the spinal cord. However, some fibers enter the RG $(E, F)$. They are located mainly in the ventral and dorsal MZs. Some fibers directly enter the ventral MZ of the caudal unrotated segments. Scale bar (in $F$ ), 100 $\mu \mathrm{m}$ for $B-F$. Cross-sectional axons (stippled); axonal processes (solid black lines).

animals in which circumferential axons altered their trajectory to project toward the ectopic floor plate, the majority of these axons projected toward the floor plate without fasciculating or contacting adjacent axons. Therefore, even those axons located farthest from the ectopic floor plate $(\approx 150 \mu \mathrm{m})$ that altered their projection appeared to be responding independently to longrange cues from the floor plate.

Ventral longitudinal pathway. The growth pattern of the earlydeveloping ventral longitudinal fibers was basically similar to that described above on E6 following HRP labeling. When the ventral longitudinal pathway was well apposed to the contralateral ventral longitudinal pathway, fibers continued to grow directly into the graft (Fig. $8 A$, single arrowheads). In other cases, many of the longitudinal fibers made medial turns at the junction. These fibers then crossed the midline, entered the contralateral ventral longitudinal pathway, and projected in the opposite direction (Fig. $7 B$ ). A few fibers appeared to project outside of the neural tube at the junctional region. Fibers crossing the junction and directly entering the lateral region of the RG were only rarely observed (Fig. 8A, double arrowheads). In summary, 

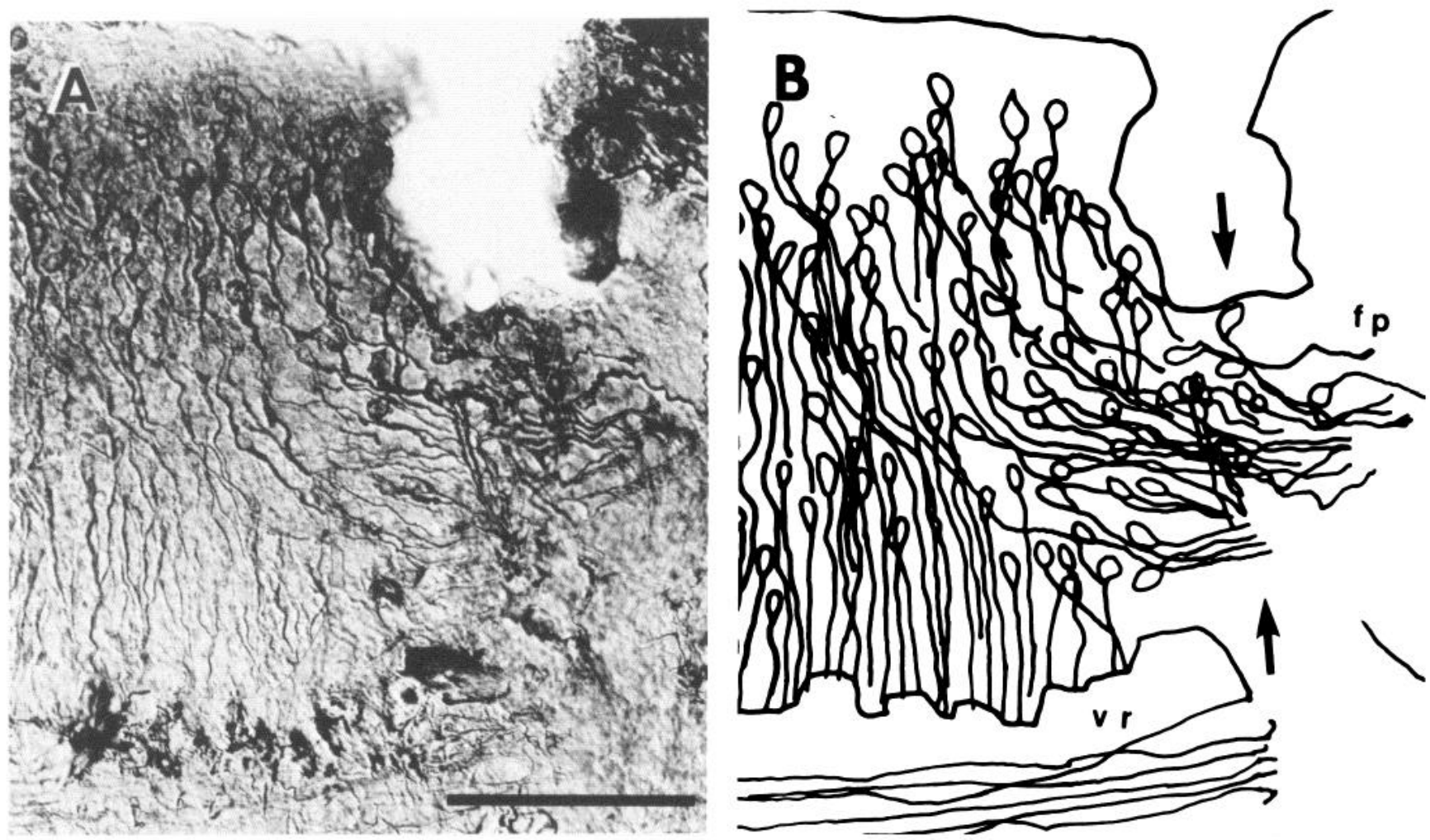

Figure 6. A photograph $(A)$ and a camera lucida drawing $(B)$ showing the early growth pattern of circumferential axons in the vicinity of the junction between the RG and unrotated segments. The lateral region of the rostral unrotated segments (left side) is apposed to the floor plate of the RG (right side). Arrows indicate the junction. Note that the circumferential axons near the junction project toward the floor plate of the RG instead of projecting ventrally as in the normal neural tube. $f p$, floor plate; $v r$, ventral root. Scale bar, $100 \mu \mathrm{m}$.

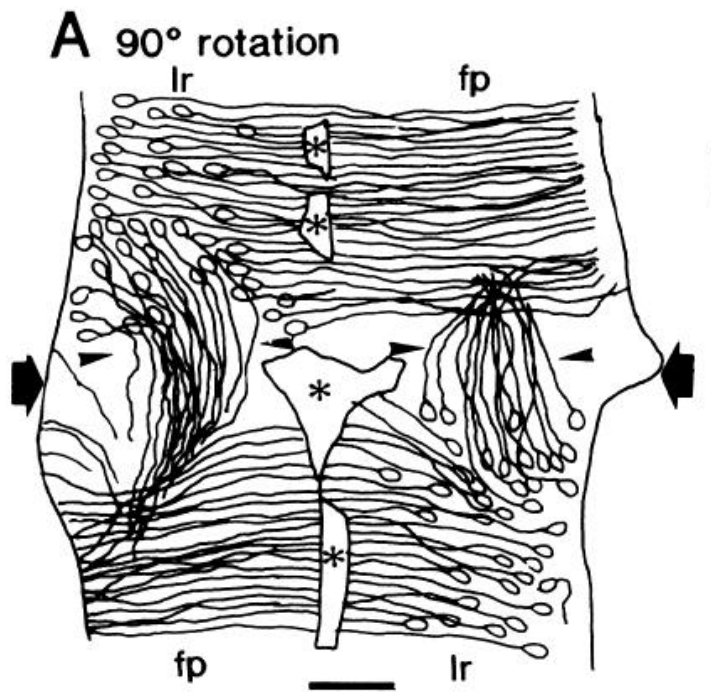

B $90^{\circ}$ rotation

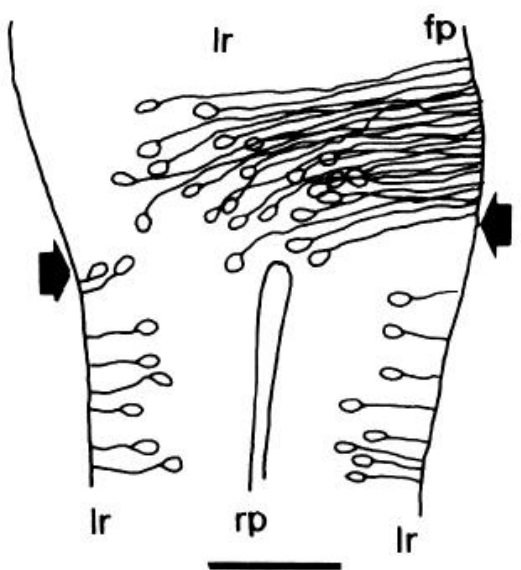

C $180^{\circ}$ rotation

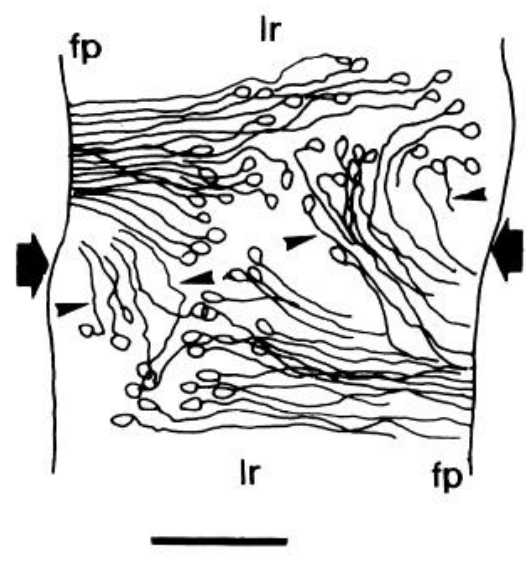

Figure 7. Camera lucida drawing showing the pattern of outgrowth of circumferential axons in the vicinity of the junction between rostral host segments and the RG after D-V rotation. Longitudinal fibers in the VF are omitted for clarity. Rostral is toward the top. Large arrows indicate the rostral junction between the host segments and the RG; asterisks indicate the ventral roots. $A$, A ventrolateral view of an animal with $90^{\circ} \mathrm{D}-\mathrm{V}$ rotation. The lateral regions of both host segments and RG are apposed with the floor plates of their counterpart. Note that circumferential axons located near the junction project toward the ectopic floor plate (between arrowheads). $B$, A lateral view of an animal with $90^{\circ}$ rotation. Here, the lateral region of the host segments is apposed to the dorsal side (roof plate) of the RG. Circumferential axons in the vicinity of the junction project ventrally toward the normal floor plate as in the control neural tube. $C$, A lateral view of a case with approximately $180^{\circ} \mathrm{D}-\mathrm{V}$ rotation. Note that the circumferential axons near the junction grow toward the ectopic floor plate by making a U-shape curve (between arrowheads). $f p$, floor plate; $l r$, lateral region of the neural tube; $r p$, roof plate. Scale bars, $100 \mu \mathrm{m}$. 
Figure 8. Camera lucida drawings showing the alteration of the trajectory of longitudinal axons in the VF at the rostral junction between the host segments and the $90^{\circ} \mathrm{D}-\mathrm{V}$ rotation $\mathrm{RG}$. Axons of C-cells are omitted for clarity. Large arrows indicate the junction. $A s-$ terisks indicate the ventral roots. Rostral is toward the top. $A$, A ventral view of a case with $90^{\circ} \mathrm{D}-\mathrm{V}$ rotation. In this case, the left VF of host segments is apposed partially with the right VF of the RG. Through this region, some longitudinal fibers grow across the junction (single arrowheads). Other longitudinal fibers make medial turns, and a few fibers project into the lateral region of the RG (double arrowheads). B, A ventrolateral view of a case with $90^{\circ} \mathrm{D}-\mathrm{V}$ rotation. Note that longitudinal fibers in the VF make medial turns and enter the contralateral VF with U-shaped turns at the junction. $v f$, ventral funiculus. Scale bars, $100 \mu \mathrm{m}$.
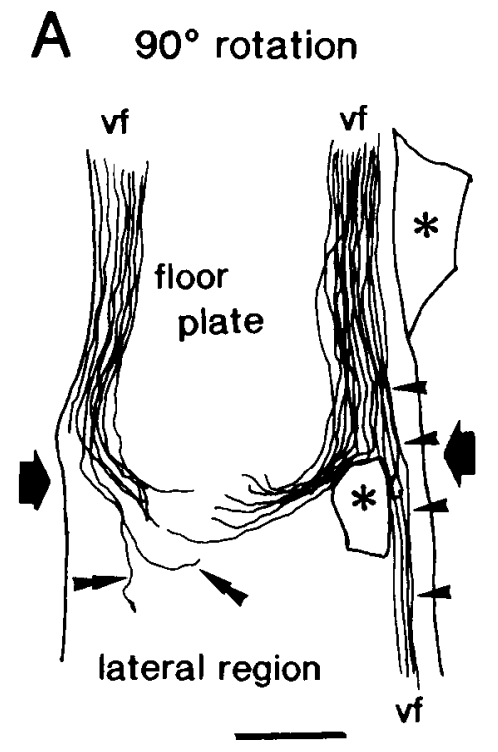

B $90^{\circ}$ rotation

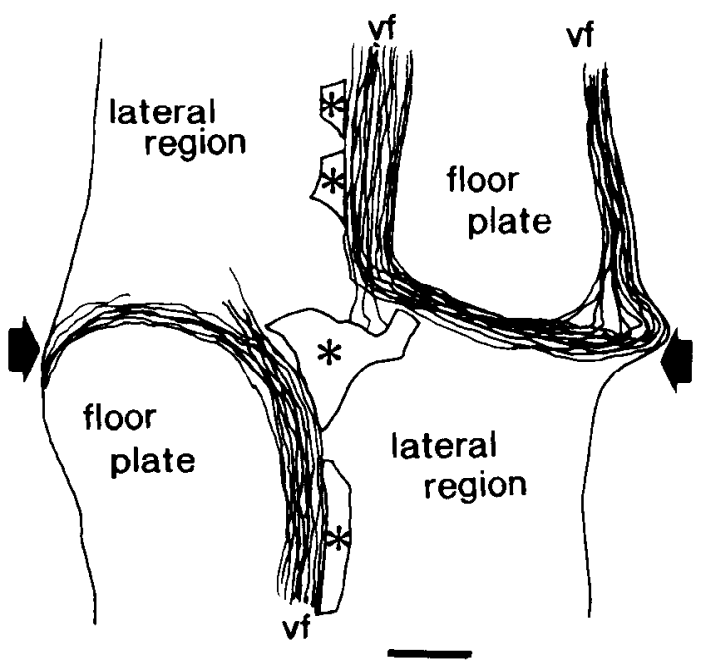

a majority of cells whose axons pioneer the ventral longitudinal pathway exhibit alterations in axonal projections following rotation at carly stages that are consistent with the pathways observed on E6. Most axons alter their trajectory so as to locate their normal pathway in the transplant.

\section{Rotation around the rostrocaudal axis ( $\mathrm{R}-\mathrm{C}$ rotation)}

Rotation of the neural tube by $180^{\circ}$ around the rostrocaudal axis creates a preparation in which the directionality of axonal projections (rostral vs. caudal) can be assessed. Thus, one can ask, for example, whether cells whose axons normally grow rostrally in the longitudinal pathways alter their direction of growth within or upon encountering the rotated cord, or whether axons arising from within the transplant alter their pathways. Although in most cases a slight structural disturbance was seen at the junction, the extent of this was much less than that seen in animals with $\mathrm{D}-\mathrm{V}$ rotation. The basic organization of the spinal cord, such as floor plate, roof plate, and slitlike central
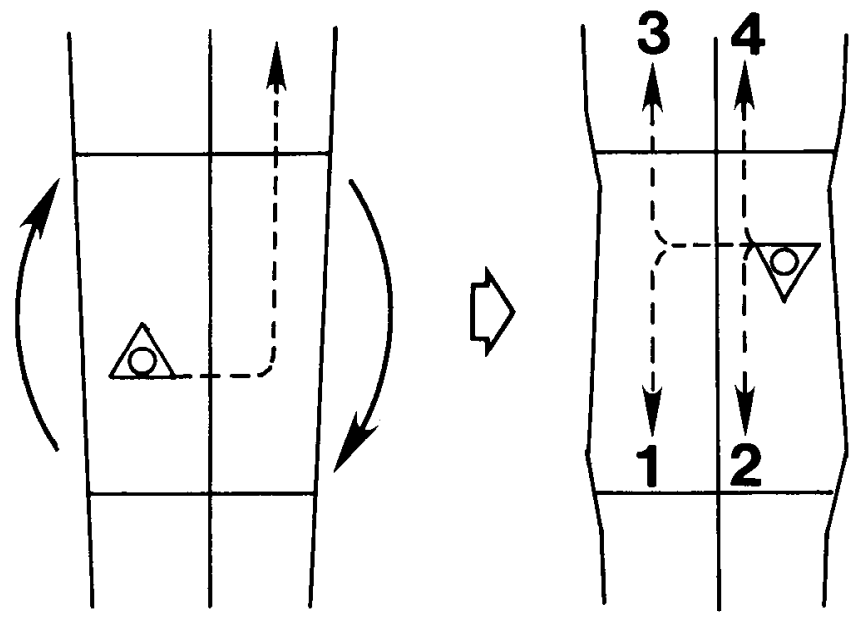

Figure 9. Diagram showing the possible pathways taken by axons of DLB-cells following rotation around the rostrocaudal axis. Ieft side, normal projection of DLB cells. Left side, following R-C rotation. For details, see Results. canal, was not altered, and a disorganized transition zone was not observed between the junction region and regions with normal structure. Obscrvations of the pattern of outgrowth of the early-developing interneurons using the antibody against neuron-specific $\beta$-tubulin revealed that circumferential axons near the junction region grew ventrally as in the normal neural tube, and that fibers in the ventral longitudinal pathway were able to pass through the junctional regions in both directions in a normal fashion as long as the ventral longitudinal pathways were well apposed (not shown).

In this series of experiments, we focused on the projection pattern of one specific group of interneurons, dorsolateral border cells (DLB-cells). As described previously (Oppenheim et al., 1988), DLB-cells are located along the dorsolateral border of the spinal cord adjacent to the dorsal $\mathrm{MZ}$ and give rise almost exclusively to ascending commissural axons. Following R-C rotation, the laterality and the rostrocaudal polarity of the rotated segments were reversed. Depending on how the DLB-cells react to this perturbation, there are four possible pathways to DLBcell projections (Fig. 9): (1) to follow the local rostrocaudal polarity of the rotated segment and to project caudally after crossing the midline, (2) to project caudally without crossing the midline, (3) to follow the general rostrocaudal polarity of the embryo and to project rostrally after crossing the midline, and (4) to project rostrally without crossing the midline. To determine the actual pathway taken by axons of the DLB-cells, we injected HRP into one side of either the rostral or the caudal junctional region on E6 and examined retrogradely labeled DLBcells both within the RG and in the segments caudal to the RG.

When HRP was injected into the rostral junctional region, labeled DLB-cells were observed both within the rotated segments and in the caudal segments (Fig. 10, Table 1). In contrast, when HRP was injected into the caudal junctional region, labeled DLB-cells were not observed within the rotated segments (Fig. 10C), whereas in most such cases, DLB-cells were observed in the segments caudal to injection (Table 1). In all cases examined, labeled DLB-cells were observed only on the side contralateral to the injection site. These results indicate that the DLB-cells in the rotated segments "adjusted" their directionality according to the general rostrocaudal polarity of the embryo, and that the DLB-cells retained their commissural nature 

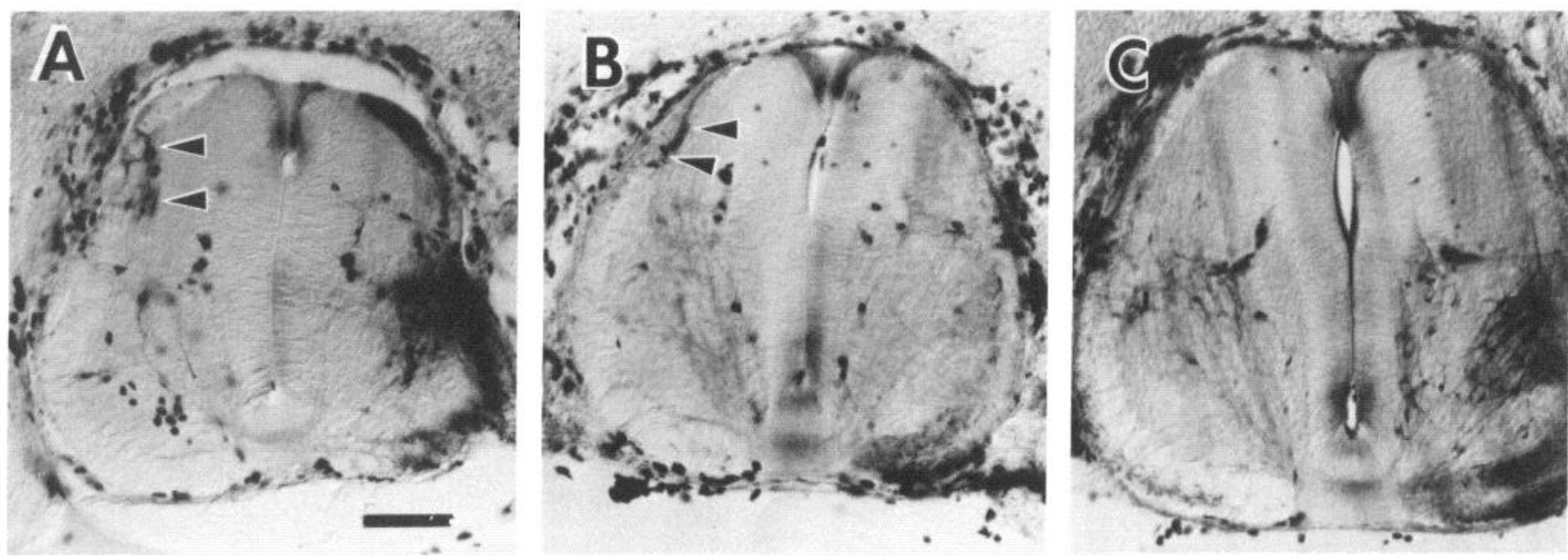

Figure 10. Photomicrographs of transverse sections through the unrotated segments $(A)$ and R-C rotation segments $(B$, $C$ ). Age of embryos is approximately E6. $A$, Unrotated control. HRP was injected into the rostral junction area. Retrogradely labeled DLB-cells were observed in the dorsolateral region of the spinal cord on the side contralateral to the injection side (arrowheads). B, R-C rotation. HRP was injected into the rostral junction region. Retrogradely labeled DLB-cells were observed in the RG (arrowheads) on the side contralateral to the injection. $C$, R-C rotation. HRP was injected into the caudal junction region. No labeled DLB-cells were observed in the RG. Scale bar, $100 \mu \mathrm{m}$.

even after their laterality was reversed. The fact that labeled DLB-cells were observed in the caudal segments following injections into the rostral junctional region indicates that axons of the DLB-cells can grow through the rostrocaudally rotated segments without difficulty. Direct observations of DiI-labeled DLB-cell axons growing through the rotated segments and into the host rostral cord confirm this (Fig. 11). Furthermore, these
DiI preparations demonstrate that the axons of DLB-cells located within the transplant project circumferentially across the ventral midline and then turn rostrally, similar to control DLBcells (Fig. 11). There was no apparent disturbance in the projection pattern of these axons either at the point at which they turned to grow longitudinally or at the junction between rotated and unrotated cord.

Table 1. Summary of the frequency of retrogradely labeled DLB-cells

\begin{tabular}{|c|c|c|c|}
\hline \multirow[b]{2}{*}{ Injection site } & \multirow[b]{2}{*}{$\begin{array}{l}\text { Case } \\
\text { number }\end{array}$} & \multicolumn{2}{|c|}{ Labeling of DLB-cells } \\
\hline & & $\begin{array}{l}\mathrm{R}-\mathrm{C} \\
\text { rotation } \\
\text { segments }\end{array}$ & $\begin{array}{l}\text { Segments } \\
\text { caudal to } \\
\text { rotated segment }\end{array}$ \\
\hline Rostral junctional region & $\begin{array}{l}298 \\
307 \\
314 \\
315 \\
318 \\
319 \\
320 \\
330 \\
338 \\
344 \\
504 \\
505 \\
506 \\
507 \\
510 \\
511\end{array}$ & $\begin{array}{l}++ \\
- \\
++ \\
+ \\
++ \\
++ \\
++ \\
++ \\
+ \\
+ \\
++ \\
+ \\
++ \\
+++ \\
+++ \\
+++\end{array}$ & $\begin{array}{l}++ \\
+ \\
+ \\
\pm \\
+ \\
+ \\
+ \\
+++ \\
\pm \\
++ \\
++ \\
+ \\
+++ \\
+++ \\
+++ \\
++\end{array}$ \\
\hline Caudal junctional region & $\begin{array}{l}345 \\
364 \\
501 \\
502 \\
503 \\
508 \\
509 \\
512\end{array}$ & $\begin{array}{l}- \\
- \\
+ \\
- \\
- \\
- \\
- \\
-\end{array}$ & $\begin{array}{l}+++ \\
++ \\
+++ \\
+++ \\
+++ \\
+++ \\
+ \\
++\end{array}$ \\
\hline
\end{tabular}

Data are from retrogradely labeled DLB-cells in the R-C RG and in segments caudal to the RG following either rostral or caudal injection of HRP; these cells were observed only on the side contralateral to the injection. The pluses indicate an estimate of the number of retrogradely labeled DLB-cells. 

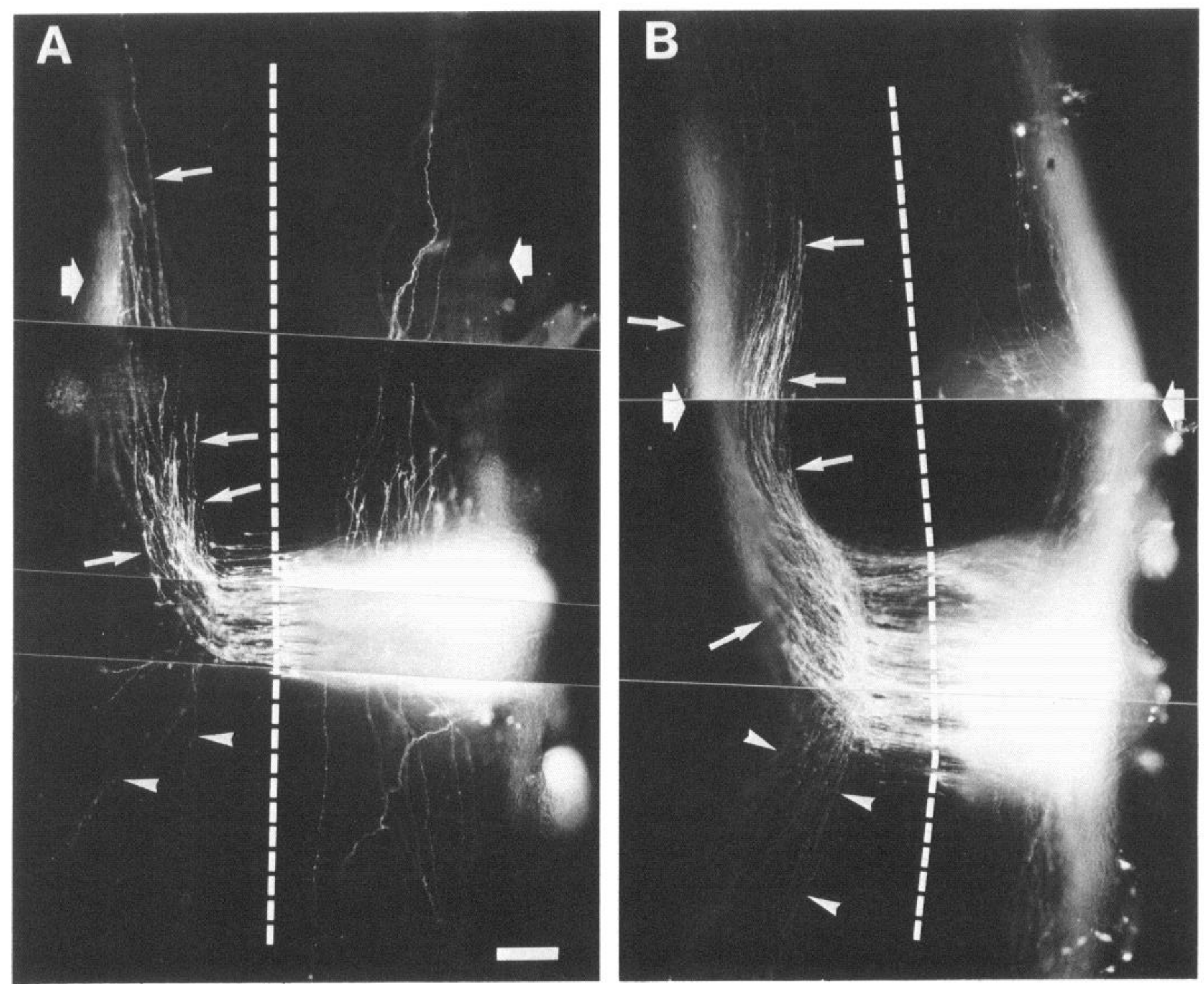

Figure 11. Photomontages of ventral views of whole-mount preparations of the thoracic neural tubes from an unrotated control operation $(A)$ and from an R-C rotation $(B)$ following DiI injection into the dorsal regions of the manipulated segments to show the course of commissural fibers. Both photomontages include the rostral unmanipulated segments as well as manipulated segments. Large arrows indicate the junction between host and transplant. Broken lines indicate the midline. Small arrows indicate the commissural fibers that turned rostrally after crossing the midline. Arrowheads indicate the few caudally projecting commissural fibers. $A$, In an unrotated control animal, most of the labeled commissural fibers turn rostrally and project through the junction. $B$, In an animal with R-C rotation, though some commissural fibers project caudally, the vast majority of commissural fibers projected rostrally. They pass through the rostral junction between host and transplant without any apparent disturbance. Scale bar, $100 \mu \mathrm{m}$.

Transplantation of the brainstem into thoracic segments (BS transplantation)

Because spinal interneurons that project to the brain (supraspinal) develop relatively late (Oppenheim et al., 1988), and because many spinal interneurons never project to the brain, it was of interest to determine whether axons that either never encounter brain tissue or only do so at later stages can nonetheless navigate through brain tissue placed in their pathway in the spinal cord. Hindbrain grafts transplanted into the thoracic segments developed histological features characteristic of the hindbrain up to at least E6 (cf. Fig. 12A,B). Although at this stage the basic structure of the normal (in situ) and transplanted hindbrain resembles that of the spinal cord (cf. Figs. $2 A, 12 A$ ), they can be distinguished by the striking differences in the structure of the roof plate. At the junctional region between the hindbrain graft and the spinal cord, only minor structural disturbances were observed. However, as long as the dorsoventral axes were in register, the basic structure was preserved around the junctional region, and a disorganized transition region was not observed.

To examine the fiber course of the longitudinal pathway, HRP was injected into the spinal cord rostral to the transplanted hindbrain graft, and retrogradely and anterogradely labeled fibers were observed in serial transverse sections. In the example presented in Figure 13, labeled fibers were observed mainly in the ventral and lateral MZs of the segments rostral to the graft. Many of these labeled fibers could be traced through the trans- 

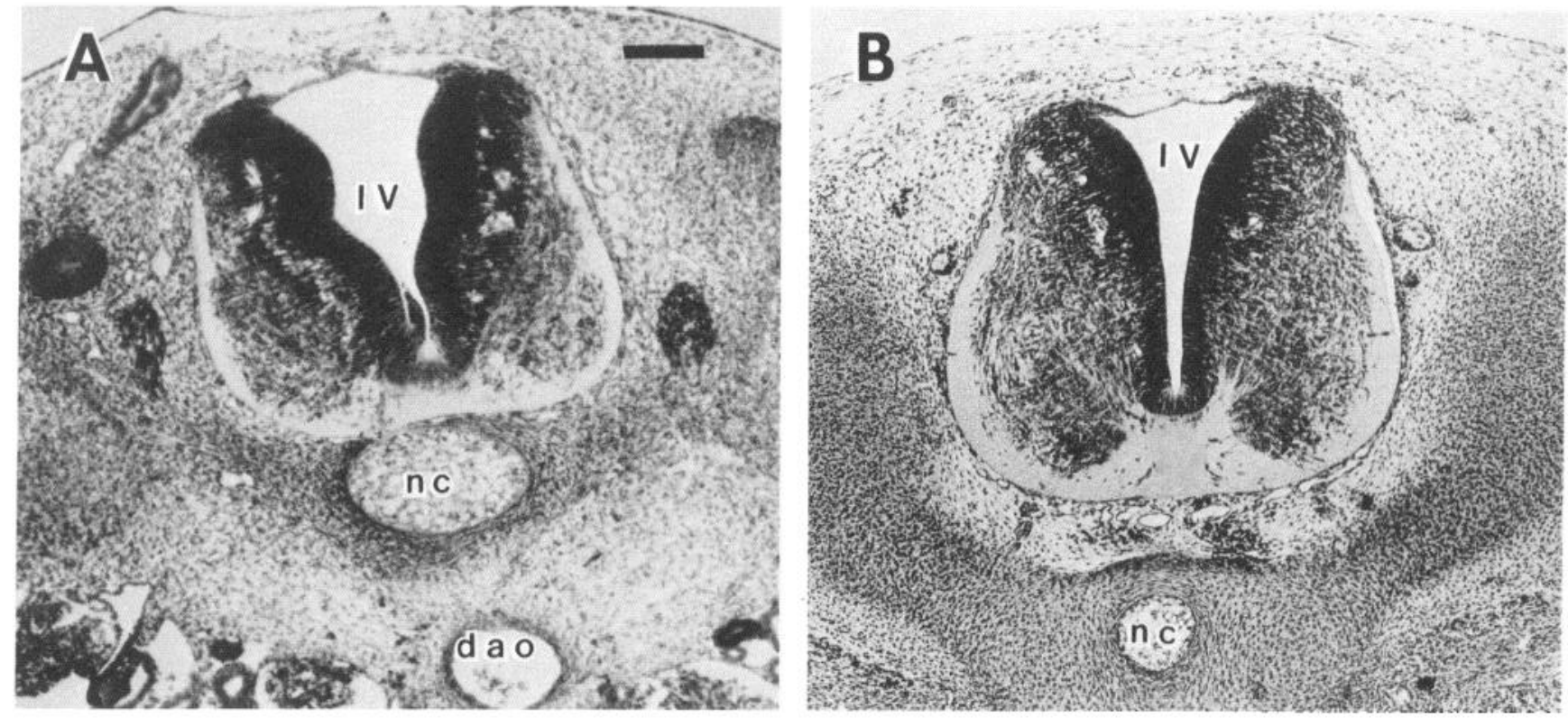

Figure 12. Photomicrographs of transverse sections through the thoracic segments of an E6 embryo that received a brainstem transplantation $(A)$, and through the hindbrain level of a normal E6 embryo $(B) . I V$, fourth ventricle; $n c$, notochord; dao, dorsal aorta. Scale bar, $100 \mu \mathrm{m}$.

plant to segments caudal to the graft. Little disturbance was seen at the junctional regions. Retrogradely labeled cells were observed in the segments caudal to the graft, and they could be categorized into several groups as in the normal spinal cord; though not quantified, their numbers appeared similar to controls (Oppenheim et al., 1988). In a few cases, $\beta$-tubulin immunocytochemistry was used to observe the early projections of host axons into the brainstem transplants on E3.5. Similar to the results from HRP labeling on E6, host axons appeared to project along normal pathways within the transplant at the very initiation of pathway formation (data not shown). Therefore, axons of spinal interneurons that normally never encounter the brainstem (propriospinal) or that only encounter brainstem pathways later in development (supraspinal ascending) can nonetheless grow into and navigate normally through this "foreign" tissue.

\section{Discussion}

In the present study, both alteration and persistence of normal projection patterns of spinal interneurons were observed following various kinds of perturbations. These results provide evidence for specific putative mechanisms of axonal guidance and also increase our understanding of the nature of such cues in the avian spinal cord.

Holley and Silver (1987), Holley (1987), and Yaginuma et al. (1991) examined the projection pattern and microenvironment of the circumferential (C-cell) axon pathways, using serial thin sections. They found that the axons grow ventrally in a nonfasciculative fashion and that there is no apparent structural basis for axonal guidance. Based on these observations, Holley and Silver (1987) proposed a gradient hypothesis, whereby chemotactic, differential adhesive, or electrical gradients in the dorsoventral plane serve as cues for ventrally directed projections. More recently, Tessier-Lavigne et al. (1988) reported that, in vitro, the floor plate of the rat neural tube is the source of a putative diffusible chemotropic factor(s) that, at a certain point along the commissural C-cell fiber dorsoventral trajectory, acts selectively to attract them toward the floor plate. The results of the present in vivo study provide additional evidence for the notion that the floor plate exerts a chemotropic-like effect on the directional projections of circumferential axons in vivo. Following $90^{\circ}$ or $180^{\circ} \mathrm{D}-\mathrm{V}$ rotation of the neural tube, it was observed that $\mathrm{C}$-cell axons changed their direction so that they projected toward floor plate regions that are ectopic for these axons, and that the distance over which this effect occurred was about $150 \mu \mathrm{m}$ from the site of the ectopic floor plates. Furthermore, the observation that the "misdirected" circumferential axons grew toward the ectopic floor plate without fasciculating, which is their normal mode of growth (Holley and Silver, 1987; Yaginuma et al., 1990), indicates that even the misdirected axons located farthest from the ectopic floor plate were responding to long-range putative chemotropic cues from the floor plate (Tessier-Lavigne et al., 1988). These in vivo observations are consistent with the idea that the floor plate secretes a diffusible factor(s) and that the diffusion gradient of this factor acts to guide the C-cell axons toward the floor plate. However, from the results of the present study, we cannot determine whether the floor plate attracts only commissural C-cell axons or if it also attracts the axons of association C-cells. In the chick, it is known that some of the C-cell axons enter the ipsilateral VF (Holley and Silver, 1987; Shiga et al., 1990; Yaginuma et al., 1990), and with available markers we are unable to distinguish these from commissural $\mathrm{C}$-cell axons before they turn longitudinally. However, in vitro studies in the rat indicate that the putative chemotropic floor plate factor acts only on the commissural axons and not on ipsilateral associational axons (Tessier-Lavigne et al., 1988).

It appears that turning medially is a primary behavior for longitudinally projecting axons in the VF when they encounter tissue of the D-V RG, which has been morphologically altered by the transplantation. Following the medial turns, however, many fibers enter the appropriate pathway in the RG, whereas 


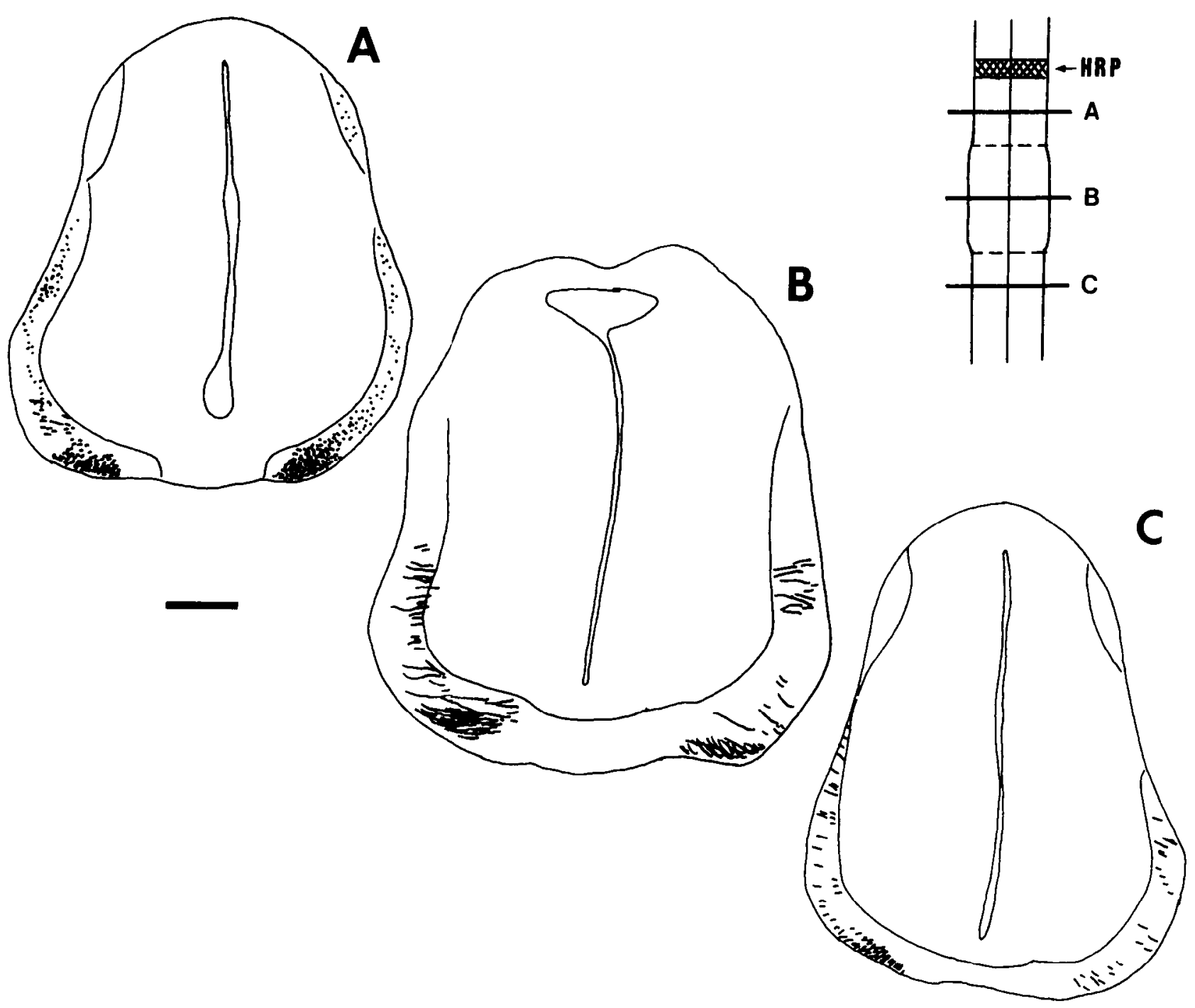

Figure 13. Camera lucida drawing of transverse sections of the spinal cord with brainstem transplantation. Levels of the sections are indicated in the inset. Note that many labeled longitudinal fibers could be followed into the segments caudal to the brainstem transplant, except for fibers in the dorsal MZ. $A$ and $C$ are from regions rostral and caudal to the brainstem transplant, and $B$ is through the center of the transplant. Scale bar, $100 \mu \mathrm{m}$.

other fibers enter the contralateral VF to project in a direction opposite to their normal direction. However, in both cases, axons were able to alter their trajectory so as to find their "normal" pathway in the MZ. What cues are responsible for causing the longitudinal fibers in the VF to turn medially at the junction? One possible explanation is that positional cues provided by the $\mathrm{VF}$ arc diffusible and that this factor attracts the contralateral fibers. According to this view, longitudinal fibers are unable to make a U-turn within the ipsilateral VF because of intrinsic constraints on turning (Katz and Lasek, 1985) and therefore turn toward the contralateral VF. However, we consider this an unlikely possibility. We have observed that, in those cases where the host VF is apposed to the VF of the RG, some longitudinal fibers still make medial turns, though in this case the ipsilateral $\mathrm{VF}$ of the RG was much closer to the turning fibers than was the contralateral VF of the unrotated segments (Fig. 5A,C). An alternative and more likely explanation for the medial turning by the longitudinal fibers is that the floor plate acts to attract longitudinal fibers in the VF. Many of the longitudinal fibers in the VF originate from commissural C-cells (Windle and Orr,
1934; Oppenheim et al., 1988; Yaginuma et al., 1990). As discussed above, commissural C-cell axons exhibit an apparent chemotropic affinity for the floor plate. If they retain this affinity even after they begin to project longitudinally, then they would be forced to turn medially toward the floor plate when they can no longer grow longitudinally. Alternatively, specific adhesion molecules on the floor plate cells may play a role in the aberrant medial-turning behavior of the longitudinal fibers. Recently, floor plate-specific adhesion molecules have been reported in the chick (Ranscht and Dours, 1989) and in the mouse (Chuang and Lagenaur, 1990), and these molecules may provide the longitudinal fibers with a more adhesive substrate than other tissues in their pathway following D-V rotation.

The results of the D-V rotation experiments reported here demonstrate that the majority of labeled longitudinal fibers in the VF that entered the RG chose the VF of the RG as a preferred pathway for axonal projections. A similar pathfinding ability of axons following perturbation was demonstrated in the axons of dorsal root ganglion cells in frogs, in which the axons were able to reach the dorsal funiculus (DF) in $180^{\circ} \mathrm{D}-\mathrm{V}$ rotation segments 
of the spinal cord (Holder et al., 1987). It has also been demonstrated that both frog retinal ganglion cells and Mauthner's cells that are placed in ectopic locations preferentially projected in specific longitudinal tracts (Constantin-Paton and Capranica, 1976; Katz and Lasek, 1979, 1981). The results of the present study, together with these other examples, indicate that many axons prefer particular pathways and that whenever possible they will alter their trajectory in order to locate the correct pathway. This is consistent with the "substrate" or "labeled pathway" hypothesis (Katz and Lasek, 1979, 1981; Katz et al., 1980; Goodman et al., 1982; Raper et al., 1983b).

However, we have also observed that a small number of the labeled longitudinal fibers derived from the VF aberrantly entered the lateral funiculus (LF) of the $90^{\circ} \mathrm{D}-\mathrm{V}$ rotation RG (Fig. 2 ), and that longitudinal fibers derived from the VF or LF sometimes entered the DF of the $180^{\circ} \mathrm{D}-\mathrm{V}$ rotation RG (Fig. 5). Similar "compromises" in pathway selection by longitudinal fibers have also been reported in the Xenopus embryo. When longitudinal fibers were confronted with non-neuronal tissues by misaligned grafting, they changed their direction of elongation and took a different pathway (Huang and Jacobson, 1986). The results of the present study support the notion that pathway selection in the vertebrate spinal cord is determined by relative rather than absolute specificity for a particular pathway (Huang and Jacobson, 1986).

One interesting result of our D-V rotation cxperiments was the difference in behavior between the host VF fibers that entered the LF of the transplant compared to the fibers that entered the DF of the transplant. Although both of these pathways are aberrant, the fibers that entered the LF shifted ventrally and eventually reached their normal pathway in the VF (Fig. 2), whereas the fibers that entered the DF continued to elongate within the DF and did not make corrections to locate their normal VF pathway (Fig. 3). One possible explanation for this difference is the isolated development of the DF. At early stages of development, the DF is separated from the LF by a region lacking nerve fibers, whereas the LF and the VF are continuous and contiguous structures (Shiga et al., 1991). It is known that a certain subset of ascending fibers in the VF normally shift to the LF as they ascend the spinal cord (Nornes et al., 1980). Therefore, it seems likely that fibers that enter the LF are better able to pass easily from the LF to the VF. Directional cues guiding axons to the VF may be provided by the medial turn at the transplant junction or by unknown gradient mechanisms. In contrast, the fibers that enter the DF may be constrained to stay in the DF rather than project through the putative nonpermissive region lacking nerve fibers to reach their normal pathway in the VF. Either the absence of guidance cues or the presence of inhibitory cues in the fiberless region may prevent these axons from reaching their normal pathway. Although it is also possible that the DF at these stages provides cues that are permissive or even attractive for ventral axons, this seems unlikely. Very few ventral axons "chose" to grow into this region even though, because of the apposition of the VF and DF of host and transplant, this would have been the most direct pathway choice for maintaining longitudinal projections.

From our results, it appears to be difficult for longitudinal fibers in the LF to project dircctly into the LF of the $R G$ following $180^{\circ} \mathrm{D}-\mathrm{V}$ rotation, even though in these cases the LFs of host and rotated spinal cords were apposed. Most of the longitudinal fibers turned dorsally, advanced circumferentially, entered the contralateral LF, and only then projected rostrally at the junctional region. Part of the reason for this behavior may be the lateness of development of the LF. It has been pointed out previously that longitudinal axons normally appear later in the LF than in the VF (24-hr delay; Yaginuma et al., 1990; Shiga et al., 1991). Therefore, when the longitudinal fibers in the LF reach the junctional region, bundles of circumferentially projecting axons that comprise the VF are already present and may serve as a barrier or as a more permissive pathway, thereby preventing the longitudinal fibers in the LF from directly entering the RG. Instead of growing directly into the transplant, they may instead follow the circumferential axons across the midline.

From the data presented here, it would appear that laterality, rostral-caudal polarity, and to some extent rostral-caudal location of axonal projections are not specified in any absolute sense in the VF. As long as there is a good apposition between rotated and unrotated regions, longitudinal fibers are ablc to elongate into the VF, even though their laterality or rostrocaudal polarity is reversed. Longitudinal fibers in the VF can project within the contralateral VF in the direction opposite from normal after making a U-turn, and they can also project through the ventral MZ of a hindbrain graft. Similar results have been reported in the frog spinal cord. In Xenopus embryos, longitudinal fibers can cross the junction and continue to elongate in rostrocaudally reversed spinal cord following head-to-head or tail-to-tail grafts (Huang and Jacobson, 1986). In Rana temporaria tadpoles, it was observed that, following $180^{\circ} \mathrm{D}-\mathrm{V}$ rotation of spinal cord, central axons originating from the dorsal root ganglion made a U-turn at the caudal transplant junction and projected aberrantly on the contralateral side (Holder et al., 1987). The guidance cues used in the funiculi of the spinal cord seem to be different from those used in the optic tract of Xenopus. Harris (1989) reported that, following rotation of small pieces of presumptive optic tract of Xenopus by $180^{\circ}$, which corresponds to the $\mathrm{R}-\mathrm{C}$ rotation experiment in the present study, optic fibers were often blocked or severely disorganized, and concluded that, in addition to a mechanical pathway, stable positional markers also influence the direction of axonal growth.

Perhaps the most striking observation of the present study concerns the alteration of axonal projections of the DLB-cells following R-C rotation. Similar alterations have been reported in the projection of axons of Mauthner's cells following similar experimental perturbations (Detwiler, 1940; Hibbard, 1965). Because the DLB-cells represent a relatively homogeneous population of identifiable vertebrate spinal neurons, the guidance cues used by these neurons have begun to receive considerable attention. One possible source of guidance cues for these cells may be the axons comprising the association longitudinal pathway. When the axons of the commissural neurons, including DLB-cell axons, arrive at the contralateral ventral $\mathrm{MZ}$, a longitudinal pathway has already been formed by pioneer axons of association neurons (PL-cells and association C-cells; Yaginuma et al., 1990). Close contacts between these preexisting longitudinal fibers and newly arriving commissural growth cones have been observed (Yaginuma et al., 1991). As discussed above, longitudinal fibers can extend directly through the junction between the unrotated and the rostrocaudally rotated segments. Longitudinal fibers originating from normally oriented segments may provide the axons of DLB-cells with rostral directional cues. In related studies in grasshopper (Goodman et al., 1982; Raper et al., 1983a,b, 1984; Bastiani et al., 1984) and fish (Kuwada, 1986) embryos, it has been shown that fasciculation onto 
specific populations of preexisting longitudinal fibers is important for the normal outgrowth and navigation of late-developing longitudinal fibcrs. Although it has not been determined what specific cellular and molecular cues are provided by preexisting axons that impart rostrocaudal directional information to latearriving axons in either insects or vertebrates, some type of gradient mechanism seems likely. An alternative explanation for the results following $\mathrm{R}-\mathrm{C}$ rotation that we cannot exclude is that the neutral tube becomes respecified by extrinsic signals following rotation so that the factors that characterize rostral-caudal guidance cues develop like normal, unrotated cord. According to this view, the stage at which the rotations were done (ST1415) would represent a time prior to complete determination of rostral-caudal characteristics. This appears to be the case for the avian tectal primordium following $180^{\circ} \mathrm{R}$-C rotation (H. Ichijo, personal communication). Tectal rotation prior to ST 15 results in normal retinotectal projections, whereas rotation after this time results in aberrant projections.

Histological examination of the region around the junction between the unrotated segments and the D-V rotation RG (transition zone) has revealed that disorganization of the spinal cord extended approximately $200 \mu \mathrm{m}$ from the junction. One reason for this disorganization can be attributed to the disturbed projection pattern of the circumferential neurons in this zone, as discussed above. However, there were also abnormalities in the ventricular zone and roof plate. In the normal spinal cord at these stages, the ventricular zone is widest in the dorsal (alar plate) region and thinnest in the ventral (basal plate) region, reflecting the temporal gradient of the generation of cells along the ventral-to-dorsal direction (Hamburger, 1948; Nornes and Das, 1972, 1974; Hollyday and Hamburger, 1977; Nornes and Carry, 1978). Normally, the roof plate lacks a marginal layer, presumably because of the existence of keratan sulfate, which is known to inhibit axon elongation in vitro and which may prevent axonal growth both across the midlinc and longitudinally in this region in vivo (Snow et al., 1990). Following $180^{\circ}$ $D-V$ rotation, the normal difference in the thickness of the ventricular zone along the dorsoventral axis disappears, and an ectopic marginal layer containing axons is formed in the region of the roof plate. These results suggest that some aspects of basic dorsoventral organization of the spinal cord may be determined by signals located outside of the neural tube, such as the notochord or adjacent mesenchyme (e.g., Placzek et al., 1990; Yamada et al., 1991) and that these signals may be somehow perturbed in the transition zone following transplantation.

The axons of many interneurons in the avian spinal cord are intersegmental or propriospinal, and even those that are supraspinal (especially those in more caudal regions) only reach the brain at relatively late stages (e.g., E6 and later; Oppenheim et al., 1988). Nonetheless, these axons are able to project into and through brainstem tissuc transplanted into the spinal cord. Furthermore, the pathways taken through the MZ of the transplanted brainstem are similar to those utilized by spinal axons when navigating through the spinal cord. Therefore, it seems likely that the brainstem (i.e., hindbrain) can express the same cues used for pathway formation by spinal axons as the spinal cord itself, even though many spinal axons never encounter brainstem pathways during normal development. This capacity may be intrinsic to brainstem or may be induced following early transplantation of the brainstem to the spinal cord. The failure of many spinal axons to project into the brainstem during normal development may result from more compelling interme- diate cues for pathway formation and synaptogenesis within the spinal cord that preclude some spinal axons from ever reaching the brainstem. Nonetheless, because some spinal axons (ascending supraspinal) normally project to the brain, it seems reasonable that pathway cues similar to those in the spinal cord should be present for maintaining these axons within the correct longitudinal trajectory in the brainstem.

\section{References}

Bastiani MJ, Raper JA, Goodman CS (1984) Pathfinding by neuronal growth concs in grasshoppcr cmbryos. III. Selective affinity of $\mathrm{G}$ growth cone for the P cells within the A/P fascicle. J Neurosci 4:23112328 .

Chuang W, Lagenaur CF (1990) Central nervous system antigen p84 can serve as a substrate for neurite outgrowth. Dev Biol 137:219232.

Constantin-Paton M, Capranica RP (1976) Axonal guidance of developing optic nerves in the frog. I. Anatomy of the projection from transplanted eye primordia. J Comp Neurol 170:17-32.

Detwiler SR (1940) Unilateral reversal of the anteroposterior axis of the medulla in Amblystoma. J Exp Zool 84:13-22.

Dodd J, Jessell TM (1988) Axon guidance and the patterning of neuronal projections in vertebrates. Science 242:692-699.

Goodman CS, Raper JA, Ho RK, Chang S (1982) Pathfindings by neuronal growth cones in grasshoppcr cmbryos. Symp Soc Dev Biol 40:275-316.

Hamburger V (1948) The mitotic patterns in the spinal cord of the chick embryo and their relation to histogenetic processes. J Comp Neurol 88:221-284.

Hamburger V, Hamilton HL (1951) A series of normal stages in the development of the chick embryo. J Morphol 88:49-92.

Harris WA (1989) Local positional cues in the neuroepithelium guide retinal axons in embryonic Xenopus brain. Nature 339:218-221.

Hibbard E (1965) Orientation and directed growth of Mauthner's cell axons from duplicated vestibular nerve roots. Exp Neurol 13:289301.

Holder N, Clarke JDW, Tonge D (1987) Pathfinding by dorsal column axons in the spinal cord of the frog tadpole. Development 99:557587.

Holley JA (1982) Early development of the circumferential axonal pathway in mouse and chick spinal cord. J Comp Neurol 205:371382.

Holley JA (1987) Differential adhesivity of neuroepithelial cells and pioneering circumferential axons. Dev Biol 123:389-400.

Holley JA, Silver J (1987) Growth pattern of pioneering chick spinal cord axons. Dev Biol 123:375-388.

Hollyday M, Hamburger V (1977) An autoradiographic study of the formation of the lateral motor column in the chick embryo. Brain Res 132:197-208.

Huang S, Jacobson M (1986) Neurites show pathway specificity but lack directional specificity or predetermined lengths in Xenopus embryos. J Neurobiol 17:593-604.

Ichijo H, Fujita S, Matsuno T, Nakamura H (1990) Rotation of the tectal primordium reveals plasticity of target recognition in retinotectal projection. Development 110:331-342.

Jacob HJ, Christ B, Jacob M, Ahlström P (1976) Differenzierung des neuralrohes. Experimentelle untersuchungen an hühner- und wachtel embryonen. Acta Anat 94:204-220.

Katz MJ, Lasek RJ (1979) Substrate pathways which guide growing axons in Xenopus embryos. J Comp Neurol 183:817-832.

Katz M.J, Lasek RJ (1981) Substrate pathways demonstrated by transplanted Mauthner axons. J Comp Neurol 195:627-641.

Katz MJ, Lasek RJ (1985) Early axon patterns of the spinal cord: experiments with a computer. Dev Biol 109:140-149.

Katz MJ, Lasek RJ, Nauta HJW (1980) Ontogeny of substrate pathways and the origin of the neural circuit pattern. Neuroscience 5:821833.

Kuwada JY (1986) Cell recognition by neuronal growth cones in a simple vertebrate embryo. Science 233:740-746.

Narayanan CH (1970) An experimental analysis of the determination of cell patterns in the spinal cord of the chick embryo. J Comp Neurol 139:189-198. 
Nordlander RH, Singer M (1982) Spaces precede axons in Xenopus embryonic spinal cord. Exp Neurol 75:221-228.

Nornes HO, Carry M (1978) Neurogenesis in spinal cord of mouse: an autoradiographic analysis. Brain Res 159:1-16.

Nornes HO, Das GD (1972) Temporal pattern of neurogenesis in spinal cord: cytoarchitecture and directed growth of axons. Proc Natl Acad Sci USA 69:1962-1972.

Nornes HO, Das GD (1974) Temporal pattern of neurogenesis in spinal cord of rat. I. An autoradiographic study-time and sites of origin and migration and settling patterns of neuroblasts. Brain Res 73:121-138.

Nornes HO, Hart H, Carry M (1980) Pattern of development of ascending and descending fibers in embryonic spinal cord of chick: I. Role of position information. J Comp Neurol 192:119-132.

Okado N, Oppenheim RW (1985) The onset and development of descending pathways to the spinal cord in the chick embryo. J Comp Neurol 232:143-161.

Oppenheim RW, Shneiderman A, Shimizu I, Yaginuma H (1988) Onset and development of intersegmental projections in the chick embryo spinal cord. J Comp Neurol 275:159-180.

Placzek M, Tessier-Lavigne M, Yamada T, Jessell T, Dodd J (1990) Mesodermal control of neural cell identity: floor plate induction by the notochord. Science 250:985-988.

Ramón y Cajal S (1929) Studies on vertebrate neurogenesis (Guth L, rev and trans). Springfield, IL: Thomas, 1960.

Ranscht B, Dours MT (1989) Selective expression of a novel cadherin in the pathways of developing motor- and commissural axons. Soc Neurosci Abstr 15:959.

Raper JA, Bastiani MJ, Goodman CS (1983a) Pathfinding by neuronal growth cones in grasshopper embryos. I. Divergent choices made by the growth cones of sibling neurons. J Neurosci 3:20-30.

Raper JA, Bastiani MJ, Goodman CS (1983b) Pathfinding by neuronal growth cones in grasshopper embryos. II. Selective fasciculation onto specific axonal pathways. J Neurosci 3:31-41.

Raper JA, Bastiani MJ, Goodman CS (1984) Pathfinding by neuronal growth cones in grasshopper embryos. IV. The effects of ablating the $A$ and $P$ axons upon the behavior of the $G$ growth cone. J Neurosci 4:2329-2345.

Shiga T, Oppenheim RW, Grumet M, Edelman GM (1990) Neuronglia cell adhesion molecule (Ng-CAM) expression in the chick embryo spinal cord: observations on the earliest developing intersegmental interneurons. Dev Brain Res 55:209-217.
Shiga T, Kunzi R, Oppenheim RW (1991) Axonal projections and synaptogenesis by supraspinal descending neurons in the spinal cord of the chick embryo. J Comp Neurol 305:83-95.

Singer M, Nordlander RH, Egar M (1979) Axonal guidance during embryogenesis and regeneration in the spinal cord of the newt: the blueprint hypothesis of neuronal pathway patterning. J Comp Neurol 185:1-22.

Snow DM, Steindler DA, Silver J (1990) Molecular and cellular characterization of the glial roof plate of the spinal cord and optic tectum: a possible role for a proteoglycan in the development of axonal barrier. Dev Biol 138:359-376.

Tanaka H, Kinutani M, Agata A, Takashima Y, Obata K (1990) Pathfinding during spinal tract formation in the quail-chick chimera analyzed by species-specific monoclonal antibodies. Development 110: $565-571$.

Tessier-Lavigne M, Placzek M, Lumsden AGS, Dodd J, Jessell TM (1988) Chemotropic guidance of developing axons in the mammalian central nervous system. Nature 336:775-778.

Tosney KW, Landmesser LT (1986) Neurites and growth cones in the chick embryo. Enhanced tissue preservation and visualization of HRPlabeled subpopulations in serial $25-\mu \mathrm{m}$ plastic sections cut on a rotary microtome. J Histochem Cytochem 34:953-957.

Windle WF, Orr DW (1934) The development of behavior in chick embryos: spinal cord structure correlated with early somatic motility. J Comp Neurol 60:287-307.

Yaginuma H, Oppenheim RW, Usun OE (1988) Pathway formation by developing interneurons following perturbation of putative guidance cues. Soc Neurosci Abstr 14:871.

Yaginuma H, Shiga T, Homma S, Ishihara R, Oppenheim RW (1990) Identification of early developing axon projections from spinal interneurons in the chick embryo with a neuron specific $\beta$-tubulin antibody: evidence for a new "pioneer" pathway in the spinal cord. Development 108:705-716.

Yaginuma H, Homma S, Kunzi R, Oppenheim RW (1991) Pathfinding by growth cones of commissural interneurons in the chick embryo spinal cord: a light and electron microscopic study. J Comp Neurol 304:78-102.

Yamada T, Placzek M, Tanaka H, Dodd J, Jessell TM (1991) Control of cell pattern in the developing nervous system: polarizing activity of the floor plate and notochord. Cell 64:635-647. 